\title{
Formation and characterization of supported microporous ceramic membranes prepared by sol-gel modification techniques
}

\author{
R.S.A. de Lange, J.H.A. Hekkink, K. Keizer *, A.J. Burggraaf \\ University of Twente, Faculty of Chemical Technology, Laboratory for Inorganic Chemistry, Materials Science and Catalysis, P.O. Box 217, \\ 7500 AE Enschede, Netherlands \\ Received 5 January 1994; accepted in revised form 6 September 1994
}

\begin{abstract}
The formation is described of supported microporous membranes (by IUPAC definition $r_{\text {pore }}<1 \mathrm{~nm}$ ), prepared by modification of mesoporous $\gamma$-alumina membranes with polymeric sols. The mesoporous $\gamma$-alumina membranes, with a top-layer thickness in the order of 7-10 $\mu \mathrm{m}$, and with pore radii of $2-2.5 \mathrm{~nm}$, have a very high surface finish (mean roughness $40 \mathrm{~nm}$ ). The amorphous microporous top-layer thickness is in the order of $60-100 \mathrm{~nm}$. Gas transport properties are effectively improved as is shown by activated permeation and molecular sieve-like separation factors in the order of $50-200$ for $\mathrm{H}_{2} / \mathrm{CH}_{4}$. These microporous top-layers can be prepared from a relatively wide range of sol structures; from inorganic oligomers which are too small to result in significant scattering with SAXS, to polymeric structures with fractal dimensions in the range : $1<d_{\mathrm{f}}<2.04$, and radii of gyration between 0.8 and $4 \mathrm{~nm}$.
\end{abstract}

Keywords: Gas separation; Ceramic membranes; Microporous; Sol-gel process

\section{Introduction}

Since the introduction of inorganic membranes for commercial applications in the early 1970s, the use in many areas such as food and beverage processing, biotechnology and water treatment is expanding rapidly [1]. Nowadays, the interest of applications in emerging areas such as gas separations and membrane reactors is increasing strongly, and due to molecular sieve-like separation properties, especially microporous $\left(r_{\text {pore }}<1\right.$ nm [2]) membranes are gaining attention $[1,3]$.

The main synthesis routes for microporous ceramic membranes are modification of mesoporous (2 $\left.\mathrm{nm}<d_{\text {pore }}<50 \mathrm{~nm}[2]\right)$ systems using sol-gel methods [4-10] or by CVD techniques [11-19].

\footnotetext{
* Corresponding author.
}

Alternative methods are controlled carbonization of organics for the formation of molecular sieve carbons [20], leaching of hollow glass fibers $[21,22]$, and, more recently, zeolitic membrane systems have been developed [23-26].

In this paper the preparation of microporous membranes by sol-gel modification of mesoporous $\gamma$-alumina membranes is described. These $\gamma$-alumina membranes are prepared by a dip coating process developed by Leenaars et al. [27,28], which is basically a slip-casting process of a porous support with a colloidal solution of boehmite $(\gamma$-AlOOH $)$.

Uhlhorn et al. [29] showed that the introduction of poly(vinyl alcohol) (PVA) in the dip solution improves the membrane quality significantly since defect-free membranes are obtained. Furthermore, the addition of PVA, with molar weight $\leq 72000$ Dalton, 
did not result in a significant change in microstructure of the top-layer. By control of the dipping time and PVA content, the top-layer thickness can be varied between 1-10 $\mu \mathrm{m}$.

Modification of these $\gamma$-alumina membranes with silica sols was found to result in molecular sieve-like gas transport properties $[4,6]$. For mesoporous $\gamma$-alumina membranes, the main gas transport mechanism for weakly adsorbing gases at temperatures around room temperature or above, is Knudsen diffusion. In Knudsen diffusion the transport rate decreases as function of temperature and the ideal separation factor $\alpha^{*}\left(=F_{\mathrm{Kn}, 0 \mathrm{~A}} / F_{\mathrm{Kn}, 0 \mathrm{~B}}\right)$ is equal to the inverse square root of the ratio of the molecular masses.

For the modified membranes, however, gas transport was activated with activation energies for hydrogen in the order of $11 \mathrm{~kJ} \cdot \mathrm{mol}^{-1}$, and molecular sieve-like separation factors (e.g. $\alpha \mathrm{H}_{2} / \mathrm{C}_{3} \mathrm{H}_{6}>272$ at $260^{\circ} \mathrm{C}$, and $\alpha$ $\mathrm{H}_{2} / \mathrm{CH}_{4}=200$ at $150^{\circ} \mathrm{C}$ ) are reported [4,6]. Due to the very thin top-layer, in the order of $60-90 \mathrm{~nm}$, high permeation rates were obtained. Especially this combination of high permeation rates and high separation factors makes these membranes very attractive for industrial applications. Activated diffusion is typical for microporous materials $[3,30,31]$, and is an elegant way to prove effective modification of mesoporous membranes. The mechanism and microscopic model of micropore diffusion will be analysed and discussed extensively elsewhere $[32,33]$.

It is believed that for obtaining microporous materials.using sol-gel technology, weakly branched polymeric sols have to be used [34]. The concept behind this is that interpenetration of the polymeric structures, which takes place during consolidation (drying or thin film formation), leads to very fine pores. From the analysis of fractal structures, which concept was introduced by Mandelbrot [35], it is shown that the mean number of intersections $M_{1,2}$ of two polymeric structures with radius $r$ and fractal dimensions $D_{\mathrm{f}, 1}$ and $D_{\mathrm{f}, 2}$ can be expressed as:

$M_{1,2} \propto r^{\left(D_{\mathrm{f}, 1}+D_{\mathrm{f}, 2}-d\right)}$

where $d$ is the dimension of space $(=3)$. The number of intersections can be regarded as the reciprocal of the tendency to interpenetrate. Thus, if the fractal dimension $D_{\mathrm{f}}$ (assume $D_{\mathrm{f}, 1}=D_{\mathrm{f}, 2}=D_{\mathrm{f}}$ ) is lower than 1.5, the number of intersections decreases as $r$ increases, resulting in a higher tendency to interpenetrate for larger structures. This may lead to tiny pores, but also to densification. However, the density of the individual fractal structures is also dependent on fractal dimension and $r$, as can be seen according to:

density $\propto$ mass $/$ volume $=\frac{r^{D_{\mathrm{f}}}}{r^{3}}=r^{\left(D_{\mathrm{f}, 1}+D_{\mathrm{f}, 2-d}\right)}$

It is clear that according to relation (2) the density decreases as $r$ is increased. To optimize the microstructure, where a small pore size and a high porosity are preferred, a balance has to be found for these two partly opposing effects.

As shown before [36], we have developed a sol-gel route for the synthesis of weakly branched polymeric $\mathrm{SiO}_{2}$ sols and binary $\mathrm{SiO}_{2}$-based sols, with up to 30 mol\% $\mathrm{TiO}_{2}$ or $\mathrm{ZrO}_{2}$ or $10 \mathrm{~mol} \% \mathrm{AlO}_{1.5}$. The sols have structures ranging from very small oligomeric structures, which are too small to give rise to significant scattering with SAXS, to polymeric sols with fractal dimensions from 1.3 to 2.04 and radii of gyration in the order of 8 to $40 \AA$. Consolidation of these sols to nonsupported membranes showed that these membranes are all microporous or almost dense for nitrogen adsorption [37]. In general, the pore size distributions are bimodal, with a strong maximum at an effective pore diameter around $0.5 \mathrm{~nm}$ and a weaker maximum around $0.75 \mathrm{~nm}$.

The relation between sol structure and the final consolidated microstructure, however, could not be explained straightforwardly from an analysis of Eqs. (1) and (2), since for practical situations during membrane formation, the consolidation process is influenced by other processes as well.

If the sol polymers still possess a certain reactivity, then the ratio of the condensation rate to the evaporation rate is important. Slow drying may result in further condensation, leading to more cross-links and therefore to stronger gel structures. The resulting porosity is then high. This is shown in a microstructural comparison between thin films and monoliths prepared from the same weakly branched sol by Frye et al. [38]. It was found that almost dense ( $2 \%$ porosity, from $\mathrm{N}_{2}$ adsorption) films were obtained, while the microporous bulk sample has a porosity of $16 \%$.

The formation and characterization of these modified membranes is discussed in this paper.

Firstly, some relevant characteristics of the $\gamma$-alumina membranes will be presented, where the focus is 
on the top-layer which acts as the support for the microporous layer. The microstructure of the $\gamma$-alumina layer is expected to be a very important parameter which determines the final quality of the supported microporous top-layer. Secondly, the characterization of the microporous top-layer is discussed, where the focus is on layer thickness and structure. The range in which supported membranes can be formed is discussed based on results from gas transport experiments.

\section{Experimental}

Boehmite $(\gamma$-AlOOH) sols were used for the formation of mesoporous $\gamma$-alumina membranes [29]. Supported $\gamma$-alumina membranes were prepared by a dip coating process of $\alpha$-alumina supports (disc-shape, diameter $39 \mathrm{~mm}$, thickness $2 \mathrm{~mm}$, mean pore radius $160 \mathrm{~nm}$, porosity $50 \%$, polished with 800 grid sandpaper) in boehmite dip solutions as described extensively elsewhere $[28,29]$.

Non-supported $\gamma$-alumina membranes were prepared by pouring the dip solutions in petri-dishes, followed by overnight drying in the climate chamber (Hereaus Vötch VTRK 300) and calcining procedures analogous to the procedures for supported membranes. These non-supported membranes are prepared for the characterization of the pore structure with adsorptiondesorption techniques. The amount of top-layer material in the supported membrane is too small to characterize the pore size distribution quantitatively with the adsorption-desorption technique.

Polymeric $\mathrm{SiO}_{2}$ sols were prepared by acid catalysed hydrolysis of tetraethylorthosilicate (TEOS, Merck, p.a. grade) in ethanol with standard molar ratios of 1:6.4:0.085:3.8 TEOS-water- $\mathrm{HNO}_{3}$-ethanol (sample code: $\mathrm{StSiO}_{2}$ ). The sols were prepared by careful dropwise addition of water and acid to the TEOS-ethanol solution, followed by $3 \mathrm{~h}$ refluxing at $80^{\circ} \mathrm{C}$ under stirring.

Binary sols were prepared using titanium isopropoxide $\left[\mathrm{Ti}\left(\mathrm{O}^{i} \mathrm{Pr}\right)_{4}, \mathrm{Merck}\right.$, p.a. grade] or titanium $n$ butoxide [ $\mathrm{Ti}\left(\mathrm{O}^{\mathrm{n}} \mathrm{Bu}\right)_{4}$, Merck, p.a. grade], zirconium$n$-butoxide- $n$-butanol complex $\left[\mathrm{Zr}\left(\mathrm{O}^{\mathrm{n}} \mathrm{Bu}\right)_{4}{ }^{-}{ }^{\mathrm{n}} \mathrm{BuOH}\right.$, Alfa, p.a. grade] and aluminium-di-sec-butoxide-acetoacetic ester chelate $\left[\mathrm{Al}\left(\mathrm{O}^{\mathrm{s}} \mathrm{Bu}\right)_{2}\right.$-etac, Alfa, p.a. grade] as alkoxides for $\mathrm{SiO}_{2} / \mathrm{TiO}_{2}, \mathrm{SiO}_{2} / \mathrm{ZrO}_{2}$ and $\mathrm{SiO}_{2} / \mathrm{Al}_{2} \mathrm{O}_{3}$, respectively. A prehydrolysis process, as described in detail elsewhere [36], has been developed for the synthesis of binary sols. This process involves a prehydrolysis step of the relatively slowly reacting TEOS prior to the addition of the highly reactive transition-metal alkoxides. As a consequence, homogeneous polymeric binary sols will be obtained. Sample codes are given as SiM10, where $\mathrm{M}$ is the binary component $(\mathrm{Ti}, \mathrm{Zr}, \mathrm{Al})$ and 10 represents the molar percentage $\mathrm{MO}_{x}(10 \%)$.

$\gamma$-Alumina membranes were modified by a dip coating process, analogous to $\gamma$-alumina membrane preparation, using freshly prepared, ethanol diluted $\mathrm{SiO}_{2}$ sols and binary sols with a final oxide concentration of $0.1 \mathrm{~mol} \mathrm{MO}_{x}$ per liter. The standard dipping time is 4 $\mathrm{s}$. The membranes were allowed to dry for about $30 \mathrm{~s}$, followed by calcination under static air for $3 \mathrm{~h}$ at $400^{\circ} \mathrm{C}$ (heating and cooling rates, $25^{\circ} \mathrm{C} . \mathrm{h}$ ).

Membrane codes for silica modified membranes are given as Alx-Siy-z, where $x$ represents the number of $\gamma$-alumina layers, $y$ the number of silica layers, and $z$ refers to the membrane under discussion. Composite modified membrane codes are given as Al3-sol, where sol represents the used binary sol.

\subsection{Characterization techniques}

$\mathrm{N}_{2}$ adsorption-desorption $(77 \mathrm{~K}$ ) experiments on non-supported $\gamma$-alumina membranes were performed using a MicroMeritics ASAP 2400 adsorption-desorption equipment. Pore size calculations were performed according to the model of Barret, Joyner and Halenda (BJH) [39], which assumes cylindrical pore geometry and includes length and area of the pore walls. For the assessment of the slit-width, in case of slit-shaped pore geometry, the pore size at the inflection point in the desorption branch of the hysteresis loop is taken to calculate the Kelvin radius $\left(r_{\mathrm{K}}\right)$, where the Kelvin equation, for nitrogen adsorption at $77 \mathrm{~K}$, is given according to: $r_{\mathrm{K}}=0.408 / \log \left(P_{0} / P\right)[40]$. The cylindrical pore radius $\left(r_{\mathrm{p}, \mathrm{cyl}}\right)$ can be calculated by [2]:

$r_{\mathrm{p} \text {.cyl. }}=r_{\mathrm{K}}+t$

For slit-shaped pore geometry, the slit width $\left(d_{\mathrm{p}, \text { slit }}\right)$ is given by [2]:

$d_{\mathrm{p}, \mathrm{slit}}=r_{\mathrm{K}}+2 . t$

where $t$ is the thickness of the adsorbed layer at the inner surface of the pore, the so-called "t-layer" [40]. 
For the calculations, the desorption branch of the isotherm is used since it determines the size of smallest pore constrictions.

Permporometry experiments on supported $\gamma$-alumina membranes were performed on a home-made equipment as described elsewhere [41]. The oxygen permeation through the membrane is measured as function of the relative vapor pressure of cyclohexane. The experiment is performed in the desorption mode. At high pressures all the pores are blocked by condensed cyclohexane. By decreasing the relative vapor pressure, first the larger pores will be opened and oxygen can permeate. Since the relative vapor pressure corresponds to a certain Kelvin radius, a pore size distribution can be calculated from a plot of oxygen permeation as function of Kelvin radius. Characterization of microporous membranes with this technique, however, is not possible since at very low relative pressures micropore filling takes place and the concept of $t$-layer and meniscus cannot be used $[2,39]$.

Characterization of the surface roughness of $\gamma$-alumina and silica modified- $\gamma$-alumina membranes were performed with profilometry (Dektak 3030, Sloan Technology Corporation) and atomic force microscopy (AFM, Nanoscope II). The radius of the tip used for AFM was about $10 \mathrm{~nm}$. Layer thickness characterization was performed using conventional scanning electron microscopy (SEM, Jeol JSM 35-CF) and field-emission SEM (Hitachi S800).

For the ultra-thin microporous films, sputter profiles obtained with X-ray photo spectroscopy (XPS, Kratos XSAM 800) and scanning Auger microscopy (SAM, Perkin-Elmer PHI 600) were used as well for layer thickness characterization. Sputter rates (by $\mathrm{Ar}^{+}$-ion bombardment) for both experimental techniques are calculated from the calibrated sputter rate for dense $\mathrm{Ta}_{2} \mathrm{O}_{5}$. The relative sputter rate of dense $\mathrm{SiO}_{2}$ compared to $\mathrm{Ta}_{2} \mathrm{O}_{5}$ is 0.85 [42]. The order of the sputter rates for $\mathrm{SiO}_{2}$ is around $3 \mathrm{~nm} . \mathrm{h}^{-1}$ for XPS and $150 \mathrm{~nm} . \mathrm{h}^{-1}$ for SAM. The sputtered areas are $8 \times 8 \mathrm{~mm}$ for XPS and $1.5 \times 1.5 \mathrm{~mm}$ for SAM, while the spot sizes for analysis are $3 \mathrm{~mm}$ and $0.5-1 \mu \mathrm{m}$ diameter, respectively. The information depth for these techniques is in the order of $5 \mathrm{~nm} \mathrm{[43].} \mathrm{Due} \mathrm{to} \mathrm{the} \mathrm{insulating} \mathrm{nature} \mathrm{of} \mathrm{SiO}_{2}$, charging of the sample surface can occur during auger analysis. This could be avoided by tilting the samples at an angle of $50^{\circ}$ and the use of a very low current of $10 \mathrm{nA}$ (accelerating voltage of $3 \mathrm{kV}$ ). Also the samples were covered with gold (thickness $200 \AA$ ), where a spot of around $2 \times 2 \mathrm{~mm}$ was left free for the analysis.

Gas permeation experiments were performed by measurement of dead-end permeation with equipment as described elsewhere [32]. The disc-shaped membranes were placed in stainless steel cells (Velterop b.v., R 250), with the top-layer at the feed side. Kalrez (DuPont) sealings were used, with a measuring area of $1.911 \mathrm{~cm}^{2}$, and maximum process temperature $300^{\circ} \mathrm{C}$. The gas flow $\left(\mathrm{ml} . \mathrm{min}^{-1}\right)$ through the membrane was controlled by a mass-flow controller (Brooks, 5051); feed pressure and pressure difference over the membrane were measured using pressure transducers (Validyne). The low pressure side of the membrane was evacuated $(P<0.01$ bar).

The permeation $(F)^{1}$ is expressed in mol.m $\mathrm{m}^{-2} \cdot \mathrm{s}^{-1} \cdot \mathrm{Pa}^{-1}$ in cases where a linear relation between membrane flux and pressure was proven. Correction of the modified membrane permeation rates for the support influence are performed according to the method as described in the Appendix.

Gas separation experiments were performed using binary gas mixtures in equipment as described extensively elsewhere [32]. Experiments were performed in counter-current mode, in stainless steel membrane test cells (Velterop b.v., R 250), with Kalrez sealing and a measuring area of $1.911 \mathrm{~cm}^{-2}$. The binary gas mixture was led along the microporous top-layer at the high pressure side and argon was used as sweep gas at the permeate side, which was connected to a vacuum pump.

The separation factor $(\alpha)$, defined as the enrichment factor of one component in the permeate compared to feed composition, is given by Eq. (5):

$\alpha=\frac{y}{1-y} \frac{1-x}{x}$

where $y$ is the molar fraction of the faster permeating component in the permeate and $x$ is the molar fraction of this component in the feed.

Microporous membranes were degassed prior to the permeation and separation measurements, in order to remove adsorbed water from the micropores, by overnight heating to $200^{\circ} \mathrm{C}$ with a hydrogen flow of 1 ml.min ${ }^{-1}$ and the low pressure side connected to the vacuum pump. The gases used were $>99.9 \%$ pure.

\footnotetext{
${ }^{1} 1 \mathrm{~mol} \cdot \mathrm{m}^{-2} \cdot \mathrm{s}^{-1} \cdot \mathrm{Pa}^{-1} \equiv 1.34410^{7} \mathrm{ml} \cdot \mathrm{min}^{-1} \cdot \mathrm{cm}^{-2} \cdot \mathrm{bar}^{-1} \equiv$ $1.9310^{8} \mathrm{~m}^{3} \cdot \mathrm{m}^{-2}$.day ${ }^{-1} \cdot$ bar $^{-1}$.
} 


\section{Results}

\subsection{Pore size characterization of non-supported $\gamma$ - alumina membranes}

Results of $\mathrm{N}_{2}$ adsorption-desorption experiments on several non-supported $\gamma$-alumina have been summarized in Table 1. Samples AI and BI were prepared from standard $0.6 \mathrm{M}$ AlOOH dip solutions, which were dried overnight in the climate chamber, and calcined according to the standard procedure $\left(3 \mathrm{~h}, 600^{\circ} \mathrm{C}\right.$; $60^{\circ} \mathrm{C} \cdot \mathrm{h}^{-1}$ heating and cooling rate). Sample CI was prepared from a $0.3 \mathrm{M} \mathrm{AlOOH}$ dip solution, with the other conditions, such as PVA content, kept constant. Samples AII, BII and CII were prepared as samples AI, $\mathrm{BI}$ and $\mathrm{CI}$, but dried in the laminar flow cupboard. Due to the lower drying rate, it took 2-3 days to dry these samples. Samples D, E and F were obtained by a second calcination procedure of different fractions of sample BI for, respectively, $3 \mathrm{~h}, 700^{\circ} \mathrm{C} ; 6 \mathrm{~h}, 700^{\circ} \mathrm{C}$ and $3 \mathrm{~h}$, $750^{\circ} \mathrm{C}$; heating and cooling rates were $60^{\circ} \mathrm{C}^{-1} \mathrm{~h}^{-1}$.

The isotherms and pore size distributions of samples $\mathrm{AI}$ and CII, which are representative for this set, are given in Figs. 1 and 2, respectively. The isotherm shape is typically of type IV $[2,39]$, which is ascribed to mesoporous solids. The hysteresis loop is of type $\mathrm{H} 2$ [2]. However, it is difficult to ascribe this hysteresis type to a certain pore size and shape, since it has been observed for many porous solids of different nature. It is believed in literature that network effects must be taken into account [2]. However, based on TEM observations and liquid permeation, it was expected by Leenaars and Uhlhorn that the pore shape is likely to be slit-shaped [27-29].

Pore size calculations are performed according to cylindrical geometry ( $\mathrm{BJH}$ method [39]), where the average pore size is given (Av. $r_{\mathrm{p}, \mathrm{des}}$ ), and from the calculation of the Kelvin radius from the inflection point of the desorption branch, using cylindrical geometry $\left(r_{\text {cyl. }}\right)$ and slit shape geometry $\left(d_{\text {slit }}\right)$ to calculate the corresponding pore size.

From Table 1 it can be seen that the slower drying rate for the samples placed in the laminar fiow cupboard compared to the samples dried in the climate chamber results in only slightly lower pore sizes, but comparable pore volumes and surface areas. The effect of $\mathrm{AlOOH}$ concentration, however, is much stronger. $0.3 \mathrm{M}$ AlOOH dip solutions result in around $10-15 \%$ larger pore sizes and pore volumes. The total volume adsorbed (Fig. 1) for sample CII is considerably higher than for sample AI, and the hysteresis loop is shifted to higher relative pressures, which implies larger pore sizes, as can be seen in Fig. 2. The shape of both the isotherm and the hysteresis loop is not changed.

The influence of the second calcination procedure is only very minor for the conditions studied. As can be seen in Table 1 , the average pore radius $(\mathrm{BJH})$

Table 1

Results of $\mathrm{N}_{2}$ adsorption-desorption measurements on non-supported $\gamma$-alumina membranes

\begin{tabular}{|c|c|c|c|c|c|c|c|}
\hline Sample & $S_{\mathrm{BET}}\left(\mathrm{m}^{2} \cdot \mathrm{g}^{-1}\right)$ & $V_{\mathrm{p}, \mathrm{des}}\left(\mathrm{ml} \cdot \mathrm{g}^{-1}\right)$ & Porosity $^{\mathrm{a}}(\%)$ & $\begin{array}{l}\text { Average } r_{\mathrm{p}, \mathrm{des}} \mathrm{BJH}^{\mathrm{b}} \\
(\mathrm{nm})\end{array}$ & $P / P_{0}^{c}$ inflection & $r_{\text {cyl. }}^{\mathrm{d}}(\mathrm{nm})$ & $d_{\text {slit }}^{e}(\mathrm{~nm})$ \\
\hline $\mathrm{Al}, 3 \mathrm{~h}, 600^{\circ} \mathrm{C}$ & 262 & 0.352 & 56 & 1.88 & 0.549 & 2.18 & 2.80 \\
\hline AlI, $3 \mathrm{~h}, 600^{\circ} \mathrm{C}$ & 282 & 0.362 & 57 & 1.84 & 0.539 & 2.13 & 2.74 \\
\hline $\mathrm{BI}, 3 \mathrm{~h}, 600^{\circ} \mathrm{C}$ & 288 & 0.375 & 58 & 1.84 & 0.539 & 2.13 & 2.74 \\
\hline $\mathrm{BII}, 3 \mathrm{~h}, 600^{\circ} \mathrm{C}$ & 267 & 0.341 & 56 & 1.8 & 0.521 & 2.05 & 2.65 \\
\hline $\mathrm{Cl}, 3 \mathrm{~h}, 600^{\circ} \mathrm{C}$ & 286 & 0.438 & 62 & 2.19 & 0.585 & 2.39 & 3.03 \\
\hline $\mathrm{CII}, 3 \mathrm{~h}, 600^{\circ} \mathrm{C}$ & 287 & 0.43 & 61 & 2.09 & 0.581 & 2.37 & 3.01 \\
\hline$D, 3 h, 700^{\circ} \mathrm{C}^{\mathrm{f}}$ & 267 & 0.358 & 57 & 1.86 & 0.545 & 2.16 & 2.77 \\
\hline $\mathrm{E}, 6 \mathrm{~h}, 700^{\circ} \mathrm{C}^{\mathrm{f}}$ & 244 & 0.347 & 56 & 1.96 & 0.561 & 2.25 & 2.87 \\
\hline $\mathrm{F}, 3 \mathrm{~h}, 750^{\circ} \mathrm{C}^{\mathrm{f}}$ & 198 & 0.341 & 56 & 2.37 & 0.626 & 2.67 & 3.34 \\
\hline
\end{tabular}

${ }^{\mathrm{a}} \rho_{\gamma-\text { alumina }}=3.7 \mathrm{~g} \cdot \mathrm{cm}^{-3}$.

${ }^{\mathrm{b}}$ Average pore radius after Barret, Joyner and Halenda [41],

${ }^{\mathrm{c}} r_{\mathrm{K}}=0.408 / \log \left(P_{0} / P\right), t$ after [42].

'Cylindrical geometry: $r_{\text {cyl. }}=r_{\mathrm{K}}+t$.

eSlit-shaped geometry: $d_{\text {slit }}=r_{\mathrm{K}}+2 t$.

fSecond calcination procedure, first step: $3 \mathrm{~h}, 600^{\circ} \mathrm{C}$ ( sample BI). 


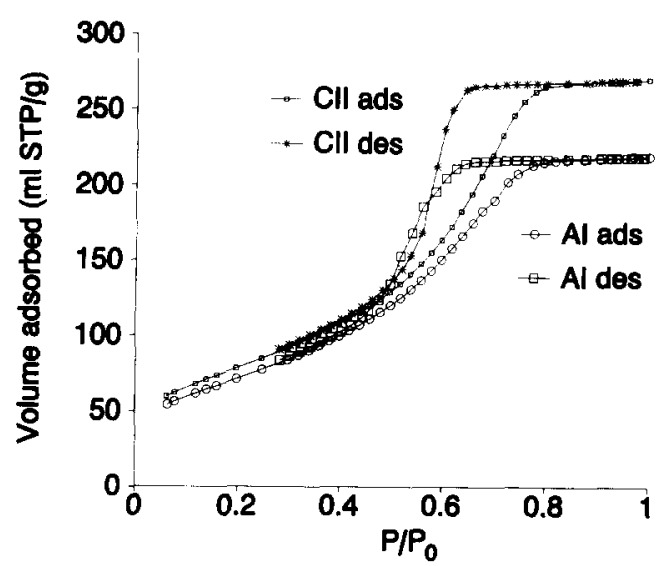

Fig. 1. $N_{2}$ adsorption-desorption isotherms of $\gamma$-alumina samples $\mathrm{CII}$ and $\mathrm{AI}$

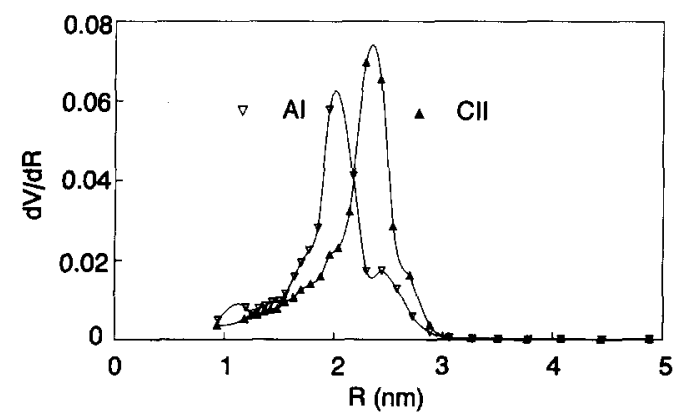

Fig. 2. Pore size distributions of $\gamma$-alumina samples CII and AI.

increases only from $1.84 \mathrm{~nm}\left(\mathrm{BI}, 600^{\circ} \mathrm{C}\right)$ to $2.37 \mathrm{~nm}$ ( $\mathrm{F}$, second step: $3 \mathrm{~h}, 750^{\circ} \mathrm{C}$ ). The pore volume is then decreased by about $9 \%$. Also it can be seen that the pore growth and pore volume decrease for sample $F$ ( second step: $3 \mathrm{~h}, 750^{\circ} \mathrm{C}$ ) is much larger compared to sample $\mathrm{E}$ (second step: $6 \mathrm{~h}, 700^{\circ} \mathrm{C}$ ) due to the higher calcination temperature.

\subsection{Pore size characterization of supported $\gamma$ - alumina membranes}

The oxygen permeation and the calculated pore size distribution (PSD), obtained by permporometry, for a representative supported $\gamma$-alumina membrane, sample Al3, is shown in Fig. 3. The membrane was prepared according to the standard synthesis route, where the $\gamma$ alumina layer was deposited in three dipping steps. Calcination took place at $600^{\circ} \mathrm{C}$ for $3 \mathrm{~h}$. In Fig. 4, the permporometry results of the same membrane are shown after a second calcination step $\left(3 \mathrm{~h}, 700^{\circ} \mathrm{C}\right)$.

The calculated PSDs give the distribution of the total number of pores within a certain range. It can be seen that the permeation at large Kelvin radii is almost zero, and that a strongly increased permeation is observed around $2-2.5 \mathrm{~nm}$. This implies that no or only a few pores are present with Kelvin radii larger than $2.5 \mathrm{~nm}$. The weak increase in permeation at Kelvin radii smaller than $2 \mathrm{~nm}$ can be ascribed to the decrease of the t-layer thickness [40]. It can be seen that the PSD is slightly sharper and shifted to larger pore sizes after the second calcination step.

The calculated maxima are given in Table 2, and are found at $r_{\mathrm{K}}=2.0 \mathrm{~nm}$ and at $r_{\mathrm{K}}=2.3 \mathrm{~nm}$. The effective pore sizes for cylindrical pore geometry and slit shape pore geometry can be calculated with Eqs. (3) and (4), respectively, where the mean thickness of the monolayer can be estimated to be approximately 0.5 $\mathrm{nm}[40,44]$. As can be seen by comparison with the

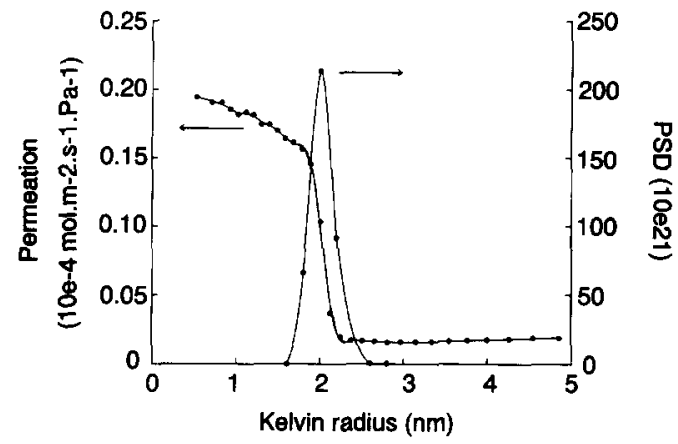

Fig. 3. Oxygen permeation and PSD (by number) as function of Kelvin radius for $\gamma$-alumina membrane $A 13$, calcined at $600^{\circ} \mathrm{C}$, determined with permporometry.

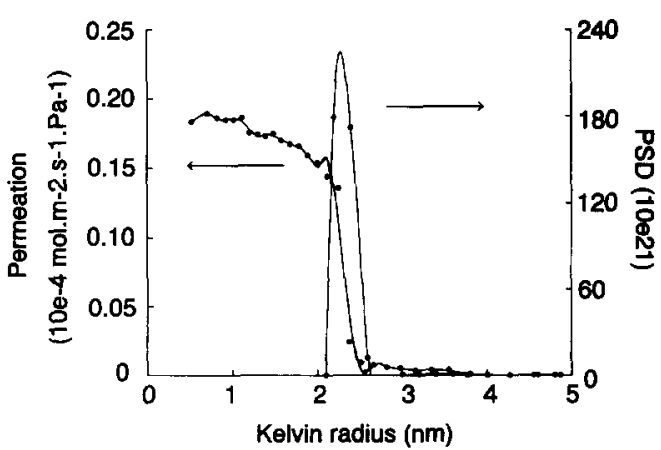

Fig. 4. Oxygen permeation and PSD (by number) as function of Kelvin radius for $\gamma$-alumina membrane $\mathrm{Al} 3$, after the second calcination step at $700^{\circ} \mathrm{C}$, determined with permporometry. 
Table 2

Calculated maxima in PSD (by number) of supported $\gamma$-alumina membrane Al3 obtained with permporometry ${ }^{\mathrm{a}}$

\begin{tabular}{llll}
\hline $\begin{array}{l}\text { Calcination procedure } \gamma- \\
\text { alumina }\end{array}$ & $r_{\mathrm{K}}(\mathrm{nm})$ & $r_{\text {cyl. }}^{\mathrm{b}}(\mathrm{nm})$ & $d_{\text {slit }}^{\mathrm{c}}(\mathrm{nm})$ \\
\hline $3 \mathrm{~h}, 600^{\circ} \mathrm{C}$ & 2.0 & 2.5 & 3.0 \\
$3 \mathrm{~h}, 600^{\circ} \mathrm{C}+3 \mathrm{~h}, 700^{\circ} \mathrm{C}$ & 2.3 & 2.8 & 3.3 \\
\hline
\end{tabular}

${ }^{\mathrm{a}} \mathrm{t}$-layer thickness $\approx 0.5 \mathrm{~nm}[46]$.

${ }^{\mathrm{b}} r_{\mathrm{cyl}}=r_{\mathrm{K}}+t$.

${ }^{\mathrm{c}} d_{\text {slit }}=r_{\mathrm{K}}+2 t$.

results obtained for non-supported membranes in Table 1 , the pore sizes for the supported membrane, as calculated by permporometry, are slightly higher after calcination at $600^{\circ} \mathrm{C}$ (compare with samples $\mathrm{AI}$ and $\mathrm{BI}$ ), and after the second calcination at $700^{\circ} \mathrm{C}$ (compare with sample D). It should be noted, that permporometry only measures the pores which contribute to the flow, dead-end pores do not contribute to the distribution, contrary to $\mathrm{N}_{2}$ adsorption-desorption.

\subsection{Surface morphology characterization of $\gamma$ - alumina membranes}

A typical cross-section of a $\gamma$-alumina membrane is shown in Fig. 5. The membrane was prepared by three dipping procedures. The top-layer thickness for this membrane is around $8-9 \mu \mathrm{m}$. The mean thickness for membranes after 3 dipping procedures was found to be $7-10 \mu \mathrm{m}$, where the thickness of the individual layers is between 2 and $3 \mu \mathrm{m}$. In ideal cases, related with sample preparation for SEM, these individual layers can be seen as showed by Zaspalis [45].

It can be seen clearly that the $\gamma$-alumina layer decreases the support roughness, which decrease is already obtained for the largest part after the first dipping step. Roughness measurements with profilometry showed that the mean roughness (defined as the mean deviation from the baseline for a certain scan length) for scan lengths of around $1 \mathrm{~mm}$ is in the order of 40 nm. Surface roughness measurements with AFM showed the same mean roughness of $40 \mathrm{~nm}$ for scan lengths of around $1 \mu \mathrm{m}$.

\subsection{Surface morphology characterization of silica modified membranes}

A three-dimensional AFM picture of a silica modified $\gamma$-alumina membrane is shown in Fig. 6. The exper- iment was performed in the so-called constant force mode, where the (electrostatic, Lennard-Jones type) repulsion force between sample and tip is maintained at zero. As can be seen clearly, the top-layer shows a surface roughness with maxima of around $20-40 \mathrm{~nm}$, which is only slightly better than the surface roughness of $\gamma$-alumina membranes.

Layer thickness characterization of silica modified $\gamma$-alumina membranes is performed with SAM, and for a single experiment with XPS, by the analysis of argon sputter profiles. The dipping time was varied from 2 to $8 \mathrm{~s}$. All samples were calcined for $3 \mathrm{~h}$ at $400^{\circ} \mathrm{C}$ (heating and cooling rates of $25^{\circ} \mathrm{C} \cdot \mathrm{h}^{-1}$ ). Also multiple $\mathrm{SiO}_{2}$ dipping experiments have been included. These membranes were first modified according to the standard procedure, with $4 \mathrm{~s}$ dipping time. After calcination a second modification was performed under identical conditions. The main goal of a second modification step is to repair possible pin-holes and/or cracks, analogous to the repair of $\gamma$-alumina membranes [29]. The digit in the used sample codes for these experiments refers to the dipping time in seconds (4-4 refers to the multiple dipped membranes), followed by a character to distinguish for the individual samples.

Representative SAM and XPS sputter profiles, for silica modified $\gamma$-alumina membrane $4 \mathrm{C}$, are shown in Figs. 7 and 8, respectively. Membrane $4 \mathrm{C}$ is prepared by dipping a standard $\gamma$-alumina membrane for $4 \mathrm{~s}$. In the SAM sputter profiles in Fig. 7 the relative concentrations of $\mathrm{Al}$ and $\mathrm{Si}$ are given as function of the sputter depth. The concentrations are calculated both from the LMM electrons and the KLL electrons. The resulting profiles resemble each other strongly. As can be seen, the concentration $\mathrm{Si}$ starts decreasing at a sputter depth of around $25 \mathrm{~nm}$, and at $45 \mathrm{~nm}$ a cross-over point in relative concentration is present. At $60 \mathrm{~nm}$ no silicon can be detected. The XPS sputter profile in Fig. 8, which also includes the oxygen concentration, has the same shape. The total thickness is equal, however, the cross-over point is at $35 \mathrm{~nm}$, which is slightly less compared to the SAM profile. The stoichiometry for both silica and alumina was found for this experiment to be around $\mathrm{MO}_{2.5}$. However, the determination of the correct stoichiometry is not reproducible due to errors in the detected oxygen concentration. Therefore, only the relative concentrations of aluminium and silicon are discussed. 


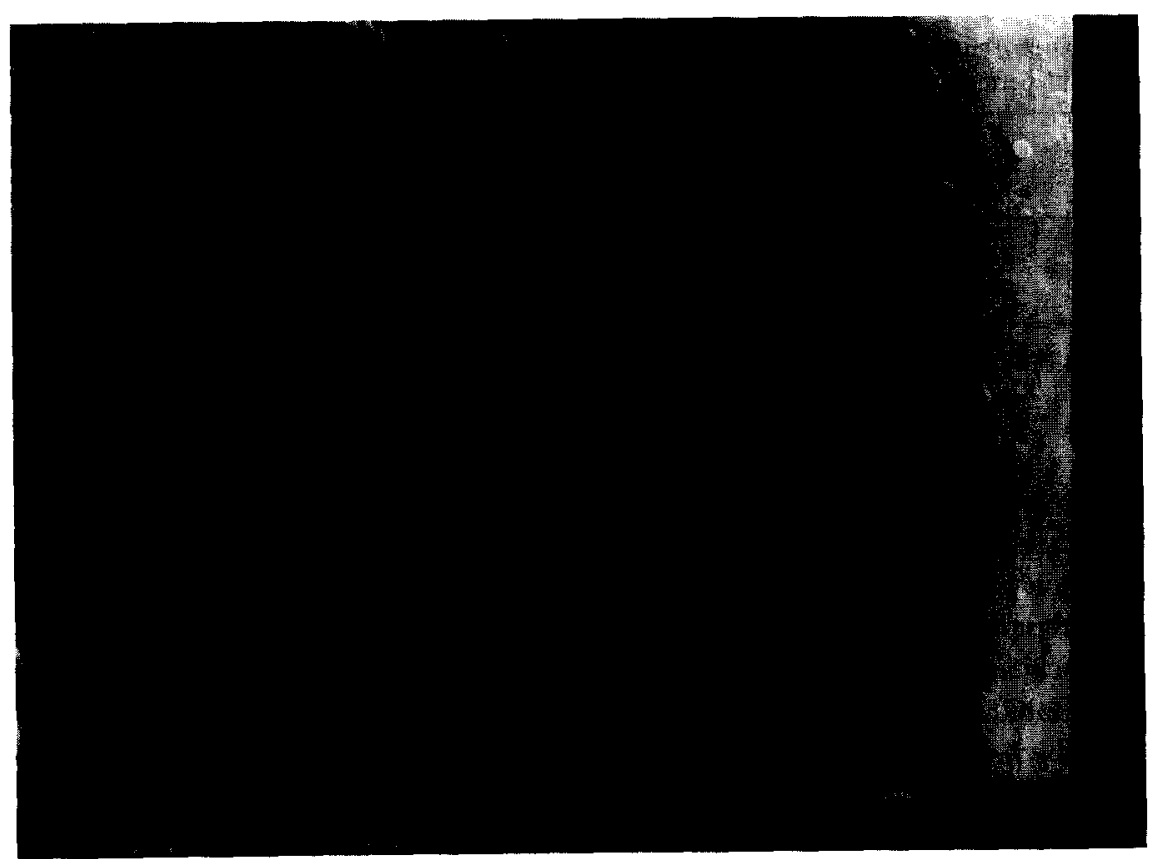

Fig. 5. SEM-micrograph of a cross-section of a three times dipped $\gamma$-alumina membrane.

Results for samples with different dipping times have been summarized in Table 3. For some samples, duplicate experiments, by taking two parts of the same membrane, have been performed. From Table 3 it can be seen that for a single membrane, the layer thickness seems to be uniform and the measurement is reproducible. Between different membranes, however, a variation in layer thickness of a factor two can occur.
The influence of the change of dipping time on layer thickness is, within the experimental error, negligible in the dipping time range of 2-8 s.

Multiple dipping of silica membranes with standard sols showed visible cracking of the top-layer in some cases, which was observed by conventional light microscopy. The membranes given in Table 3 did not show any cracking. Remarkable is that the layer thick-

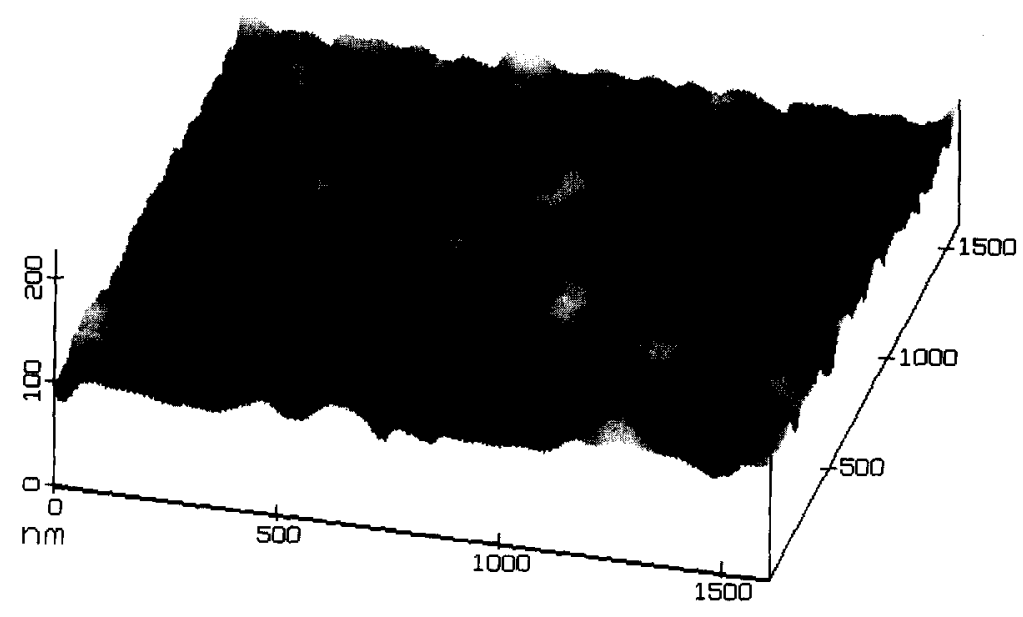

Fig. 6. Three-dimensional AFM picture of silica-modified membrane. 


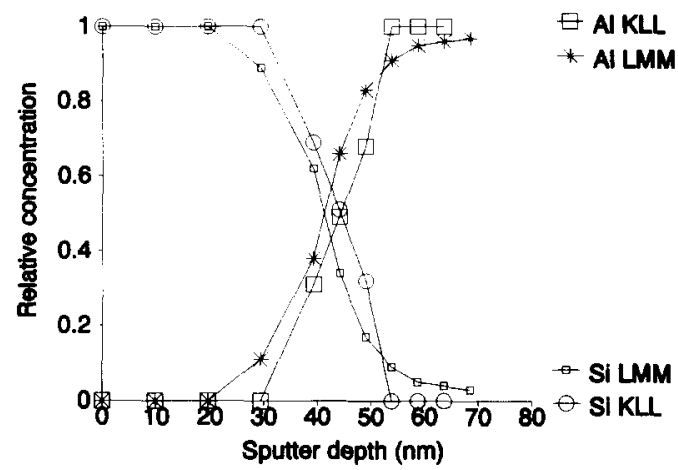

Fig. 7. SAM sputter profile silica modified $\gamma$-alumina membrane 4C.

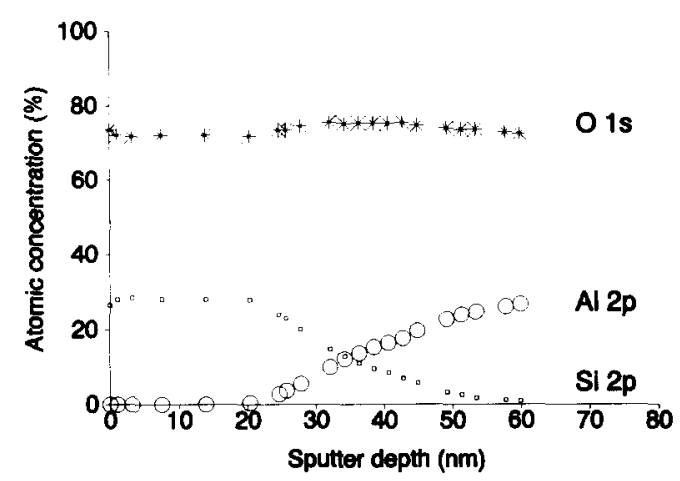

Fig. 8. XPS sputter profile silica modified $\gamma$-alumina membrane $4 \mathrm{C}$.

ness is only very slightly increased compared to the single dipped membranes.
In Fig. 9, a FE-SEM picture is shown of silica modified $\gamma$-alumina top-layer (membrane $4 \mathrm{~F}$ ). A very nice layer can be seen with a thickness of around $120 \mathrm{~nm}$, which is in agreement with the results found for SAM and XPS.

\subsection{Gas transport characterization of microporous membranes}

\section{Pure $\mathrm{SiO}_{2}$ modified membranes}

The $\mathrm{H}_{2}$ permeation and $\mathrm{CO}_{2}$ permeation as function of temperature for silica modified membrane Al3-Si1D are shown in Figs. 10 and 11, respectively. The membrane fluxes for both gases were linearly dependent on pressure, which result in practically pressure independent permeation rates. As can be seen, the permeation increases as function of temperature both for $\mathrm{H}_{2}$ and $\mathrm{CO}_{2}$. This is a clear evidence that an effective modification with a microporous top-layer is obtained, since gas permeation rates according to Knudsen diffusion or surface diffusion will decrease for increased temperatures. The calculated activation energies for permeation for the membrane system ( $\equiv \gamma$-alumina membrane + microporous $\mathrm{SiO}_{2}$ top-layer) are 11.0 $\mathrm{kJ} . \mathrm{mol}^{-1}$ for $\mathrm{H}_{2}$ and $2.0 \mathrm{~kJ}^{-\mathrm{mol}^{-1}}$ for $\mathrm{CO}_{2}$. Correction for support ( $\equiv \gamma$-alumina membrane) influence gives the true apparent activation energies for the silica toplayer, which are slightly higher; $12.3 \mathrm{~kJ} \cdot \mathrm{mol}^{-1}$ and 2.7 $\mathrm{kJ} \cdot \mathrm{mol}^{-1}$ for $\mathrm{H}_{2}$ and $\mathrm{CO}_{2}$, respectively.

Table 3

Layer thickness of microporous $\mathrm{SiO}_{2}$ top-layer obtained by SAM sputter profiles

\begin{tabular}{|c|c|c|c|c|c|}
\hline $\begin{array}{l}\text { Membrane } \\
4 \mathrm{~s} \text { dipping }\end{array}$ & $\begin{array}{l}\text { Cross-over depth } \\
\text { (nm) }\end{array}$ & $\begin{array}{l}\text { Total layer thickness } \\
(\mathrm{nm})\end{array}$ & $\begin{array}{l}\text { Membrane } \\
2,8,2 \times 4 \mathrm{~s} \\
\text { dipping }\end{array}$ & $\begin{array}{l}\text { Cross-over depth } \\
\text { (nm) }\end{array}$ & $\begin{array}{l}\text { Total layer thickness } \\
(\mathrm{nm})\end{array}$ \\
\hline $4 \mathrm{~A}$ & 40 & 60 & $2 \mathrm{~A}$ & 6590 & 80100 \\
\hline 4B & 50 & 75 & $2 \mathrm{~B}$ & 4862 & 7080 \\
\hline $4 C$ & 45 & 60 & $8 \mathrm{~A}$ & 9575 & 12090 \\
\hline $4 C^{a}$ & 35 & 60 & $8 B$ & 7870 & 100100 \\
\hline $4 D^{b}$ & $\approx 25$ & 60 & $4-4 A^{c}$ & 90 & 110 \\
\hline $4 D^{a, b}$ & 90 & $>90$ & $4-4 B^{c}$ & 110 & 140 \\
\hline $4 E$ & 8282 & 100100 & & & \\
\hline $4 F^{d}$ & & 120 & & & \\
\hline $4 \mathrm{G}^{\mathrm{d}}$ & & 150 & & & \\
\hline
\end{tabular}

abtained from XPS-sputter profiles.

'Data taken from Uhihom [4].

cPrepared in 2 modification steps with intermediate calcination.

'Obtained from FE-SEM. 


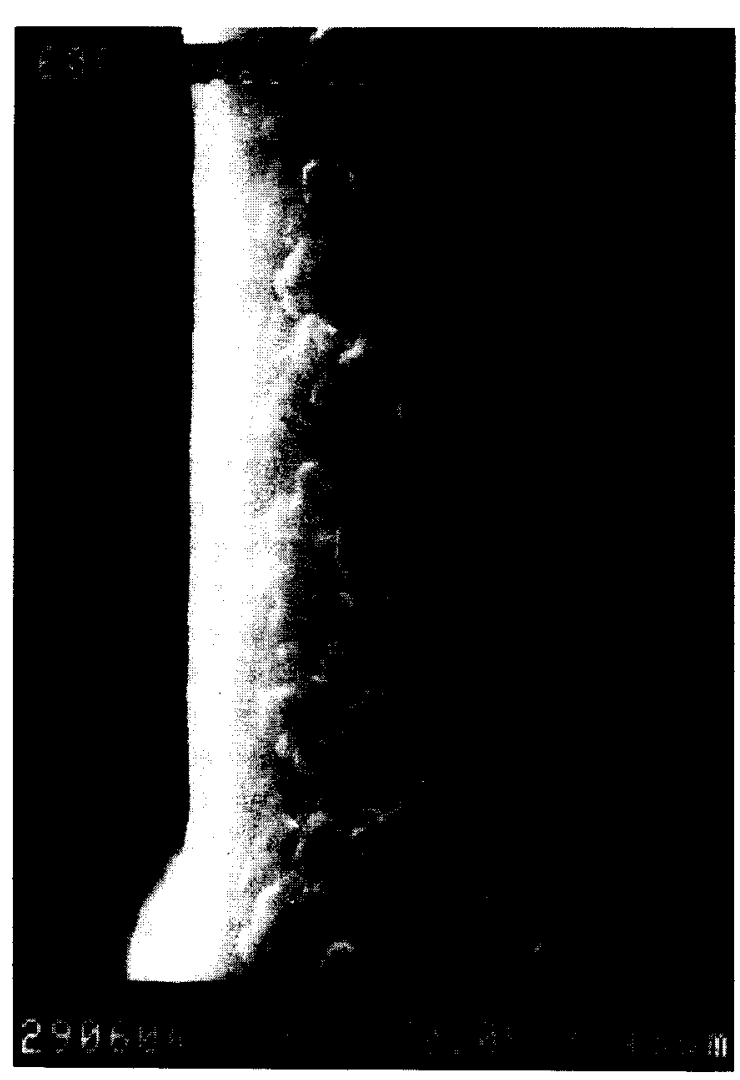

Fig. 9. FE-SEM micrograph of a cross-section of a $\gamma$-alumina toplayer modified with silica.

The effect of support correction is clearly shown for membrane Al3-Si2-A. This membrane was prepared by multiple modification with silica of a $\gamma$-alumina ( 3 layer) membrane. The second dipping procedure was intended to repair possible cracks and/or pinholes. The dip solution for this second step was prepared by diluting a standard sol 180 times, which is 10 times more diluted than for standard modification procedures for the first step. By using these very diluted sols no cracking of the top-layer was observed.

After the first modification the permeation rate for $\mathrm{H}_{2}$ at $50^{\circ} \mathrm{C}$ was around $3.7 \times 10^{-7} \mathrm{~mol} \cdot \mathrm{m}^{-2} \cdot \mathrm{s}^{-1} \cdot \mathrm{Pa}^{-1}$ (single point measurement). The $\mathrm{H}_{2}$ permeation after the second modification step is shown in Fig. 12, where both the membrane ( $\gamma$-alumina membrane + silica toplayer) permeation ( $\mathrm{M}$ ) and the top-layer (microporous silica) permeation ( $T$ ), obtained by support correction, are given. The permeation rate for $\mathrm{H}_{2}$ at $50^{\circ} \mathrm{C}$ is decreased by almost a factor two due to the second modification step. The difference between the membrane system permeation and corrected top-layer permeation increases with temperature. This is caused by the increased top-layer permeation at higher temperatures (due to activated transport), and the decreased support permeation, which follows Knudsen diffusion [Eq. (1)]. Therefore, the difference in permeation rates for support and top-layer decreases, resulting in a stronger contribution of the support to the total pressure drop over the membrane. Consequently, corrections become more important at higher temper-

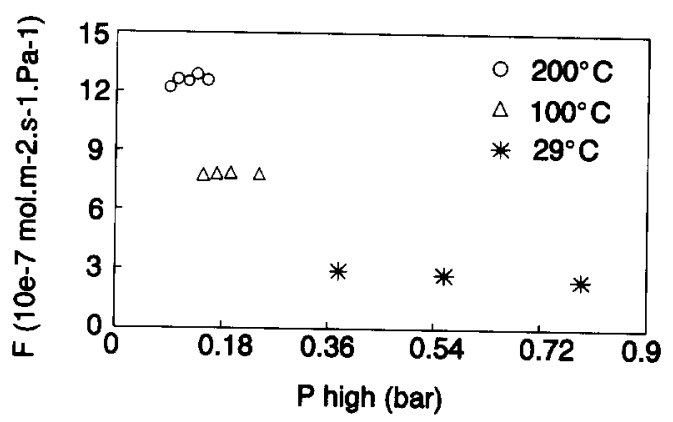

Fig. 10. $\mathrm{H}_{2}$ permeation for silica modified membrane Al3-Si1-D.

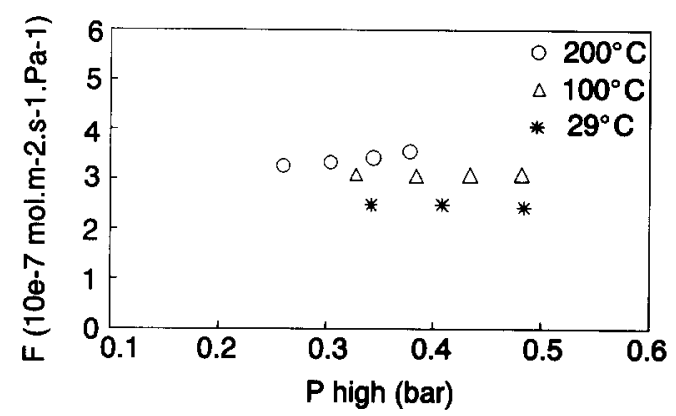

Fig. 11. $\mathrm{CO}_{2}$ permeation of silica modified membrane Al3-Sil-D.

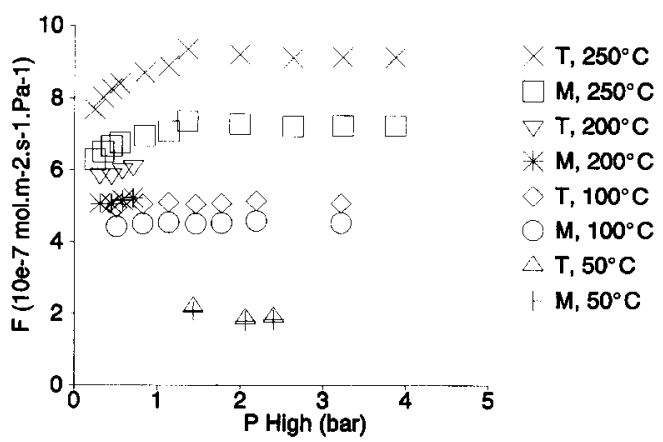

Fig. 12. $\mathrm{H}_{2}$ permeation of silica modified membrane Al3-Si2-A (M) and microporous top-layer ( $T$ ), after the second dipping step. 


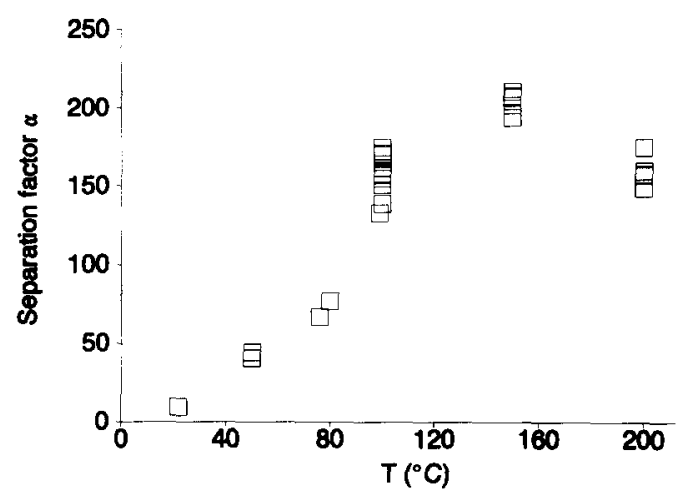

Fig. 13. $\mathrm{H}_{2} / \mathrm{CH}_{4}$ and $\mathrm{H}_{2} / \mathrm{CO}_{2}$ separation results for silica modified membrane $\mathrm{Al} 3-\mathrm{Si} 2-\mathrm{A}$ prepared by a multiple dipping procedure.

atures. This can be clearly seen in the example in the Appendix. As a consequence, the calculated activation energy for permeation for the top-layer $\left(8.2 \mathrm{~kJ} \cdot \mathrm{mol}^{-1}\right)$ is higher than for the total membrane system (7.1 $\mathrm{kJ} \cdot \mathrm{mol}^{-1}$ ).

Also it can be seen that the permeation is practically pressure independent up to 4 bar feed pressure, apart from the data points at high temperature at low pressures. The latter effect is attributed to the lower accuracy of the pressure transducers at these low pressures.

In Fig. 13 results are shown for separation experiments of $\mathrm{H}_{2} / \mathrm{CO}_{2}$, obtained after the first modification, and of $\mathrm{H}_{2} / \mathrm{CH}_{4}$, both after the first modification and the second modification step. The feed pressure was 2.7 bar and the pressure difference was 1.9 bar for these experiments. The feed composition was 50:50 with a

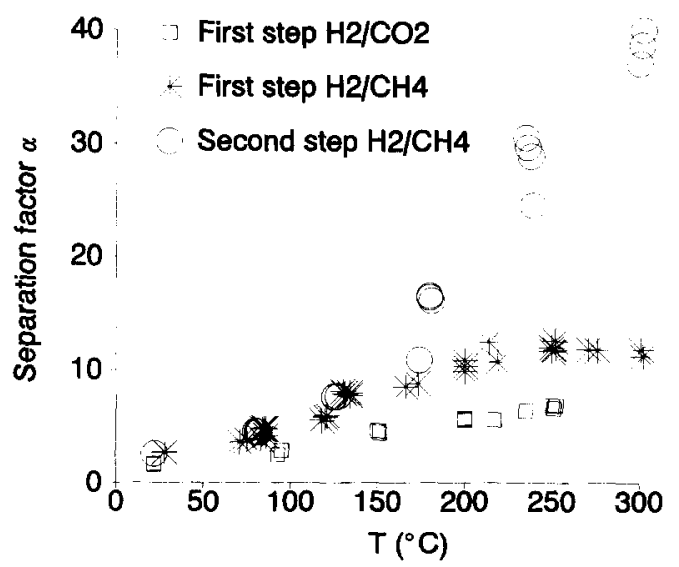

Fig. 14. $\mathrm{H}_{2} / \mathrm{CH}_{4}$ separation of microporous silica/titania modified membrane Al3-SiTi10X. flow rate of $100 \mathrm{ml} \cdot \mathrm{min}^{-1}$. The argon sweep gas flow rate was $150 \mathrm{ml} \cdot \mathrm{min}^{-1}$.

After the first modification step with silica, both the $\mathrm{H}_{2} / \mathrm{CO}_{2}$ separation factor and the $\mathrm{H}_{2} / \mathrm{CH}_{4}$ separation factor increase as function of temperature. The absolute value is for both sets higher than the ideal separation factors according to Knudsen diffusion, which are 4.69 for $\mathrm{H}_{2} / \mathrm{CO}_{2}$ and 2.83 for $\mathrm{H}_{2} / \mathrm{CH}_{4}$. The absolute separation factors, as well as the improvement of the separation factors compared to Knudsen diffusion, are higher for the $\mathrm{H}_{2} / \mathrm{CH}_{4}$ combination.

A considerable improvement of the separation factor is obtained after the second modification step. The $\mathrm{H}_{2}$ / $\mathrm{CH}_{4}$ separation factor at $300^{\circ} \mathrm{C}$ is increased from around 12 to 40 .

Composite $\mathrm{Sil}_{2} / \mathrm{TiO}_{2}$ and $\mathrm{SiO}_{2} / \mathrm{Al}_{2} \mathrm{O}_{3}$ modified membranes

Membrane Al3-SiTi10X was modified with binary $\mathrm{SiO}_{2} / \mathrm{TiO}_{2}\left(10 \mathrm{~mol} \% \mathrm{TiO}_{2}\right)$ sol SiTi10X. This sol was prepared by mixing of a $\mathrm{SiO}_{2}$ sol and a $\mathrm{TiO}_{2}$ sol, which were separately prehydrolysed, as described extensively elsewhere [36]. SAXS analysis showed that the fractal dimension of this sol was 2.04 (after 30 days) with a radius of gyration of $36 \AA$. The dried and calcined non-supported film was almost dense (porosity $2 \%$ ) [37]. Microporous membranes "Al3-SiTi10Bu2", "Al3-SiTi10Pr2" and "Al3-SiAl10 $r_{w}=4.6,70$ "' were prepared by the modification of $\gamma$-alumina membranes with the corresponding binary sols. $\mathrm{The}^{\mathrm{SiO}}{ }_{2}$ / $\mathrm{TiO}_{2}$ sols "SiTi10Bu2" and "Siti10Pr2"' were prepared by a so-called two step hydrolysis process, which involves a second hydrolysis step after the addition of the titanium alkoxide to the prehydrolysed $\mathrm{SiO}_{2}$ sol [36]. The fractal dimensions are 1.3 and the radii of gyration are $17 \AA$ for both "SiTi10Bu2" and "SiTi10Pr2". Sol "SiAl10 $\mathrm{r}_{\mathrm{w}}=4.6,70$ " was prepared by a single step prehydrolysis process. $\mathrm{SiO}_{2} / \mathrm{Al}_{2} \mathrm{O}_{3}$ sols prepared under comparable conditions showed no significant scattering in the SAXS experiments, which implies that very small oligomeric structures have been obtained.

The porosity of the microporous non-supported membranes was $28 \%$ and $27 \%$ for SiTi10Bu2 and SiTi10Pr2 respectively; non-supported membrane SiAl10 $r_{\mathrm{w}}=4.6$ was practically dense for nitrogen (porosity $1 \%$ ) [37]. 
Table 4

Selected gas transport properties of microporous sol-gel derived membranes

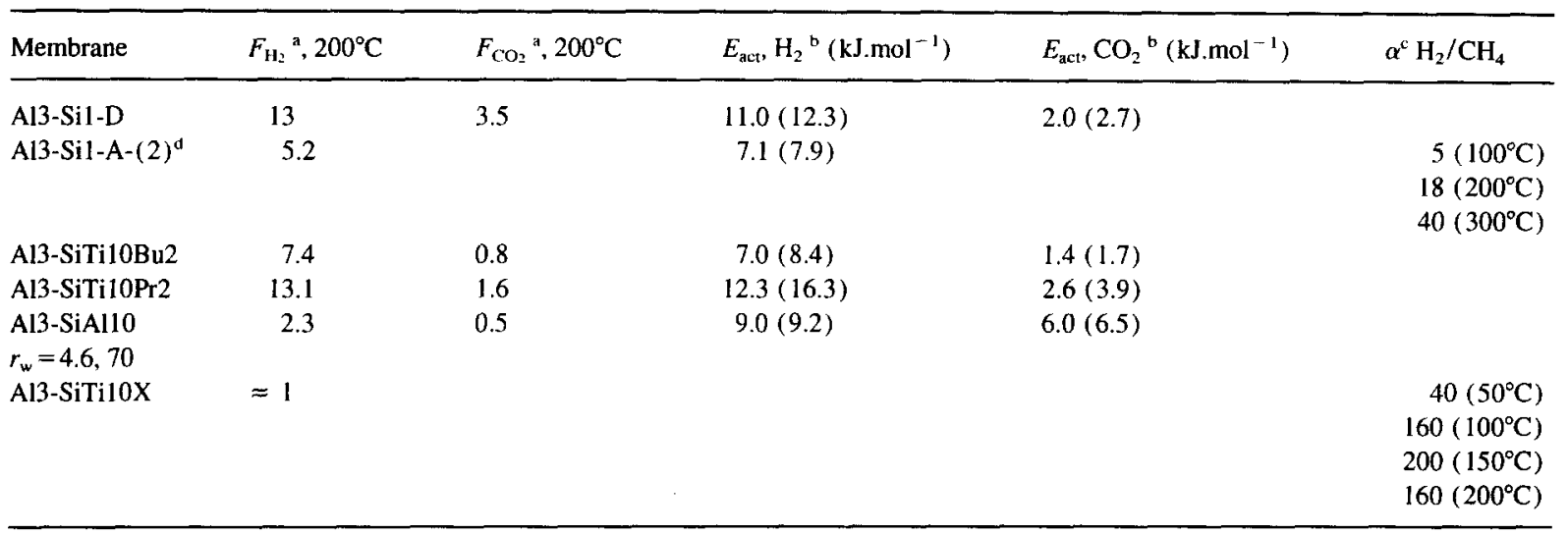

aPermeation in $10^{-7} \mathrm{~mol} \cdot \mathrm{m}^{-2} \cdot \mathrm{s}^{-1} \cdot \mathrm{Pa}^{-1}$. Linear relation between $F$ and feed pressure up to at least 3-4 bar.

${ }^{b}$ Values between parentheses corrected for support influence.

'Obtained from separation experiments with binary gas mixtures.

dData obtained after the second modification step.

$\mathrm{H}_{2} / \mathrm{CH}_{4}$ separation results for Al3-SiTilOX are shown in Fig. 14. A 50:50 feed, with a total flow rate of $200 \mathrm{ml} . \mathrm{min}^{-1}$ was used. The argon sweep gas flow rate was $200 \mathrm{ml} . \mathrm{min}^{-1}$. The feed pressure was 3.1 bar and the pressure difference over the membrane was 1.8 bar. This membrane shows extremely high $\mathrm{H}_{2} / \mathrm{CH}_{4}$ separation factors. Obviously the binary sol resulted in a microporous top-layer. As can be seen, an optimum in separation factor, is present at $150^{\circ} \mathrm{C}$.

In Table 4 some gas transport data have been summarized. The binary membranes showed activated transport as well, with activation energies in the order as have been found for silica modified membranes.

\section{Discussion}

As shown in Table 1, the lower AlOOH concentration in the dip-solutions (standard: $0.6 \mathrm{M} \mathrm{AlOOH}$ ), results in higher pore volumes and a slightly increased pore size. The PVA content for these sols, however, was not changed. Therefore, another important difference between the $0.6 \mathrm{M}$ sol and $0.3 \mathrm{M}$ sol is the ratio PVA:sol. Since the amount of PVA was kept constant, this ratio is twice as high in the $0.3 \mathrm{M}$ dip solution. An explanation may be that the application of a high PVA:sol ratio leads to a certain amount of destabilization of the sol particles [46]. This results in a less dense packed consolidated gel, and therefore higher pore volume and pore size. More work is currently going on to investigate the influence of PVA more extensively.

Comparison of the data obtained for non-supported membranes with supported membranes can be performed elegantly by the use of permporometry. As can be seen in Table 2, the calculated pore sizes are slightly higher for the supported membranes. As has been noted before, one has to recognize that permporometry characterizes only the "active" pores for permeation, deadend pores are therefore not detected. This can lead to higher mean pore sizes for permporometry.

A second explanation for the slightly higher pore size for the supported system can be given based on the effect of support constraints for the supported membranes. For supported $\mathrm{TiO}_{2}$ membranes, it was shown by Kumar et al. [47] that support constraints hinder the densification and phase transformation significantly. While for non-supported membranes the porosity was around 15-20\%, the supported membranes showed a porosity of about $25-30 \%$. The phase transformation for anatase to rutile was shifted from $650^{\circ} \mathrm{C}$ to about $850^{\circ} \mathrm{C}$. Shrinkage of the top-layer, due to either drying or sintering, results in additional tensile stresses in the top-layer originating from the rigid support. These additional stresses reduce the drying stresses and sinter stresses, which are both compressive. The sup- 
port effect was also partly attributed to the possibility of particle rearrangement, which is less for the supported membranes.

The surface roughness values for $\gamma$-alumina are comparable with results from earlier work $[48,49]$, where it was shown that both the ground support ( 800 grid sandpaper) and the $\gamma$-alumina membranes have the same roughness of $40 \mathrm{~nm}$. This final roughness looks to be an intrinsic property of the $\gamma$-alumina layer, since it cannot be improved even after multiple dipping procedures. The roughness was also not decreased, within the experimental error by the silica top-layer as we have shown.

The mean roughness of the silica top-layer and the $\gamma$-alumina membrane may be the explanation for the gradual decrease of the silica concentration as found in the sputter profiles measured with SAM and XPS. Since a relatively large area, compared to the surface roughness, is scanned during analysis, the $\gamma$-alumina layer will appear gradually during sputtering. Because of the surface roughness of around $40 \mathrm{~nm}$, a cross-over region can be expected of the same order, provided the order of the sputter rates for $\mathrm{SiO}_{2}$ and $\mathrm{Al}_{2} \mathrm{O}_{3}$ are comparable, which is the case for $\mathrm{Al}$ and $\mathrm{Si}$ [50].

Another possibility can be partly penetration of the silica in the $\gamma$-alumina pores. Since the difference between the pore diameter (around 3 or $5 \mathrm{~nm}$ for slitshaped geometry or cylindrical geometry respectively) and radius of gyration of the weakly branched silica sols ( $R_{\mathrm{g}}$ around 2 to $3 \mathrm{~nm}$ ) is not very large it is not expected that penetration takes place very deep into the $\gamma$-alumina pores. Condensation and gelation will take place in the pores, and consequently the further transport of the sol particles within the layer is hindered.

As can be seen from Table 3, the variation in layer thickness of silica membranes dipped for $4 \mathrm{~s}$ is between 60 and $100 \mathrm{~nm}$. There is no significant difference, within the experimental error, in the layer thickness for membranes dipped for $2 \mathrm{~s}$ and for $8 \mathrm{~s}$. Several effects may be responsible for this. When film formation takes place mainly by film coating, and slip casting is a very minor contribution, then the dipping time is not relevant but factors such as sol viscosity, pulling speed and surface tension are dominant [34]. Most probably slip casting is of minor importance because the resistance of flow of liquid through the formed microporous gel layer is very high and consequently the slip cast rate is low.
Since dipping takes place manually, pulling speed variations are a possible source of the scatter in layer thicknesses in the film coating process. The preliminary results presented for membranes which were modified in two steps can, within the experimental error, also be explained by this formation mechanism.

On the other hand, if slip-casting is important, the layer thicknesses would then theoretically have the ratio 1:1.41:2 for membranes dipped for 2,4 and $8 \mathrm{~s}$, since the layer thickness is proportional to the square root of the dipping time $[28,29]$. From the data available, we have to conclude that it is not likely that slipcasting is the dominant layer formation process.

Comparison of data obtained with SAM and XPS with FE-SEM cross-sections shows that the order of the calculated membrane thickness is comparable. An important cause for possible errors in the absolute calculated layer thickness from sputter profiles can be the estimate for the sputter rate. This is based on dense $\mathrm{SiO}_{2}$, whereas the membranes are porous. The comparison of the three techniques shows that no large error in the assessment has been made.

Since the membrane layer thickness is in the same order of the mean surface roughness of the support ( 40 $\mathrm{nm}$ ), we believe that the quality of the support is a very important condition for successful membrane modification. Commercially available mesoporous ceramic membranes, which are mainly tubular systems, are generally of much lower surface quality, and will consequently need additional intermediate layers of better quality before modification can be successfully performed.

The application of a second modification step is an effective method to repair the membrane quality, which has also been found for $\gamma$-alumina membranes by Uhlhorn et al. [29]. The picture which was proposed to explain this, was that during the second slip-casting step of the $\gamma$-alumina layer with boehmite (same concentration in first and second step), initially preferential deposition of a gel layer takes place at a defect, since the permeation at these places is higher than on defectfree $\gamma$-alumina.

As we have shown, the concept of membrane repair by a second dipping procedure can be applied as well for sol-gel derived microporous membranes (Fig. 13). The hydrogen permeation rate has decreased by a factor two and the separation factor was improved significantly. Since the sol concentration is very low for the 
Table 5

Comparison of sol properties, non-supported membrane characteristics and supported membrane characteristics.

\begin{tabular}{|c|c|c|c|c|c|c|c|}
\hline & \multicolumn{3}{|l|}{ Sol SAXS } & \multicolumn{2}{|l|}{ Nonsupported $^{\mathrm{a}}$} & \multicolumn{2}{|l|}{ Supported $^{\mathrm{a}}$} \\
\hline & age (days) & $D_{\mathrm{f}}$ & $R_{\mathrm{g}}(\AA)$ & Porosity $^{\mathrm{b}} \epsilon(\%)$ & $D_{\text {eff }}(\mathrm{nm})$ & $E_{\text {act }}\left(\mathrm{H}_{2}\right)\left(\mathrm{kJ} \mathrm{mol}^{-1}\right)$ & $\alpha \mathrm{H}_{2} / \mathrm{CH}_{4}$ \\
\hline $\mathrm{StSiO}_{2}$ & 01020 & 1.451 .651 .75 & 203035 & $35-40$ & $0.5 / 0.75$ & $5-17^{\mathrm{c}}$ & $30-50$ \\
\hline SiTi10Bu $r_{w}=1$ & 4 & d & d & 42 & $0.5 / 0.75$ & & \\
\hline SiTi10Bu $r_{w}=6.4$ & 4 & 1.9 & 51 & 7 & e & & \\
\hline SiTi10Pr2 & 3 & 1.3 & 17 & 27 & $0.5 / 0.75$ & 16.3 & \\
\hline SiTil0Bu2 & 3 & 1.3 & 17 & 28 & $0.5 / 0.75$ & 8.4 & \\
\hline SiTiloX & 30 & 2.04 & 36 & 2 & e & & 200 \\
\hline SiZr10 & 8 & d & d & 16 & $\approx 0.6$ & & \\
\hline SiZr $10-2 r_{\mathrm{w}}=2$ & 6 & 1.43 & 8.4 & 2 & e & & \\
\hline SiA110 $r_{w}=4.6,70$ & & & & 1 & e & 9.2 & \\
\hline
\end{tabular}

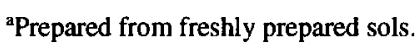

${ }^{b}$ Porosity $\epsilon$ calculated using a skeletal density of $2.2 \mathrm{~g} . \mathrm{cm}^{-3}, 2.36 \mathrm{~g} . \mathrm{cm}^{-3}, 2.40 \mathrm{~g} . \mathrm{cm}^{-3}$ and $2.31 \mathrm{~g} . \mathrm{cm}^{-3}$ for amorphous silica, silica/titania, silica/zirconia and silica/alumina, respectively.

'Data taken from [34].

dNo significant scattering.

No PSD defined.

second dipping procedure, this relatively strong decrease in permeation can not be explained by a second comparable thick layer, but it indicates that indeed defects, with very high permeation rates compared to the microporous top-layer, have been eliminated.

The higher separation factor for $\mathrm{H}_{2} / \mathrm{CH}_{4}$ compared to $\mathrm{H}_{2} / \mathrm{CO}_{2}$ as found for membrane Al3-Si2-A (Fig. 14 ) is in agreement with gas separation properties for a series of binary gas mixtures with $\mathrm{H}_{2}$ as reported elsewhere [32]. Generally it is found that the separation factor increases in the order $\mathrm{H}_{2} / \mathrm{CO}_{2}<\mathrm{H}_{2}$ / $\mathrm{CH}_{4}<\mathrm{H}_{2} /$ propene $<\mathrm{H}_{2} /$ isobutane. Differences in molecular size play a role in the separation mechanism (the kinetic diameter of methane is larger than for carbon dioxide ( $0.33 \mathrm{~nm}$ and $0.38 \mathrm{~nm}$, respectively [51] ), but also sorption phenomena are important. The exact mechanism is discussed in an extensive gas transport study $[32,33]$.

From the gas transport data summarized in Table 4 it is clear that microporous membranes have been obtained from both silica and binary sols. As has been shown before [37], microporous non-supported membranes have been obtained from a range of fractal polymeric sols. A comparison of some representative non-supported and supported membrane characteristics is given in Table 5 .

For standard silica modified membranes, the corrected activation energies are in the order of 5-17
$\mathrm{kJ} . \mathrm{mol}^{-1}$ for hydrogen. This activation energy can be regarded as a tool to judge membrane quality, as will be shown elsewhere [32].

Using this criterium, the binary membranes are within the quality range observed for silica modified membranes. Improved transport properties are observed for both membranes corresponding with nonsupported membranes with high porosities (" $\mathrm{StSiO}_{2}$ ", "SiTi10Pr2" and "SiTi10Bu2") and non-supported membranes with low porosities ("SiTi10X" and "SiAl10"). The permeation rates, which are in the order of $15 \times 10^{-7} \mathrm{~mol} \cdot \mathrm{m}^{-2} \cdot \mathrm{s}^{-1} \cdot \mathrm{Pa}^{-1}$ for $\mathrm{H}_{2}$ at $200^{\circ} \mathrm{C}$ for ' $\mathrm{StSiO}_{2}$ ", however, are a factor 3-10 lower for the latter two membranes, as can be seen in Table 4 . These low permeation rates are approximately proportional to the difference in porosity found for these non-supported membranes prepared from these sols compared to pure silica.

These very interesting, molecular sieve-like, transport properties, show that the pore size of the supported membranes is very small, and in the order of the pore sizes found for the non-supported membranes. Based on the relatively high permeation rates of these membranes, and on the order of the activation energy, it can be concluded that transport takes place through micropores, and not through a dense layer. In comparison with dense quartz glass (activation energies of 38 $\mathrm{kJ} . \mathrm{mol}^{-1}$ for hydrogen [52]), the activation energy 
for permeation is low. Moreover, the permeation rates found for the sol-gel derived membranes are high. The hydrogen permeation through dense quartz glass at $500^{\circ} \mathrm{C}$, with a layer thickness of $0.1 \mu \mathrm{m}$, has found to be in the order of $1 \times 10^{-8} \mathrm{~mol} \cdot \mathrm{m}^{-2} \cdot \mathrm{s}^{-1} \cdot \mathrm{Pa}^{-1}$ [53]; at $200^{\circ} \mathrm{C}$ the permeation will be of the order of $2 \times 10^{-10} \mathrm{~mol} \cdot \mathrm{m}^{-2} \cdot \mathrm{s}^{-1} \cdot \mathrm{Pa}^{-1}$., which is more than a factor 1000 lower than for hydrogen permeation for the sol-gel derived membranes described in this work.

The relation between fractal dimension, porosity of the non-supported membranes and supported membrane properties is not straightforward.

Very low porosities for non-supported membranes have been found for both sols with high fractal dimensions (samples "SiTil0Bu, $r_{\mathrm{w}}=6.4$ " and "SiTi10X"), moderate fractal dimension ("SiZr102") and sols with polymers too small to show significant scattering ("SiAl10"). Relatively high porosities have been found for samples with low fractal dimensions ("SiTi10Bu, $r_{\mathrm{w}}=1$ " and 'SiZr10") and moderate fractal dimensions ("StSiO ${ }_{2}$ ", "SiTi10Bu2" and "SiTi10Pr2").

The sol properties of supported $\mathrm{SiO}_{2} / \mathrm{TiO}_{2}$ modified membranes using sols "SiTi10Pr2" and "SiTi10Bu2" are comparable with standard silica sols. It looks therefore not surprisingly that membrane properties are comparable as well. However, supported membranes using "SiTi10X" and 'SiAl10, $r_{\mathrm{w}}=4.6,70$ " also give rise to comparable gas transport properties. The sol structures, however, are significantly different. "SiTi10X" has a fractal dimension of 2.04 , which is relatively high compared to the silica sols. The fractal dimension of the corresponding $\mathrm{TiO}_{2}$ sol used as one of the components in this mixed sol was 2.2. The $\mathrm{SiO}_{2}$ sol used for the mixed sol consists of very small oligomers; sols prepared under comparable conditions showed no scattering with SAXS. Although the sol age for the measurement was 30 days, it is not expected to deviate significantly from a freshly prepared sol, since the concentration is very low, which effectively retards further growth [36]. Since scattered intensity of $\mathrm{TiO}_{2}$ is stronger than for $\mathrm{SiO}_{2}$, the $\mathrm{TiO}_{2}$ signal will dominate the spectrum. The formation of microporous materials from sols with such a high fractal dimension is not expected directly from the analysis based on fractal structures using Eqs. (2) and (3). A possible explanation that for this case indeed a microporous consolidated material was obtained is that the sol consists of a distribution of fractal structures. The main phase consists of the very weakly branched silica and a minor phase consists of the branched $\mathrm{TiO}_{2}$. This also may explain the rather low permeation rate.

The membrane prepared from "SiAl10 $r_{\mathrm{w}}=4.6,70$ " showed a very low permeation rate. The structure of the used sol is probably oligomeric since no scattering was observed. Interpenetration of these oligomers therefore results in a low porosity.

Further, we have observed that increasing the water content in the binary sol synthesis always leads to less porous materials [37], which is very remarkable, since the fractal dimensions increase [36]. Obviously, the addition of more water for the binary sols results in internal condensation of the already formed structures. If no further growth takes place, the final radius of gyration can still be low. In spite of the fact that interpenetration of these denser structures is hindered, denser consolidated structures are formed.

For an explanation of the observation that dense materials are obtained from sols with high fractal dimension, the size of the polymers has to be taken into account as well. As can be seen from Eq. (2), the number of intersections $M_{1,2}$ for sols with $D_{\mathrm{f}}>1.5$, which is the case for this discussion, increases as $r$ is increased. The tendency to interpenetrate is therefore low. The porosity of the individual polymers, however, decreases for higher fractal dimensions. The cumulative effect can be an almost dense system. Obviously the effect of the decreased porosity of the individual structures prevails in the formation mechanism, and the tendency to interpenetrate is less important.

The discussed observations show that a prediction of the porosity of the consolidated material based on fractal dimension and interpenetration alone is difficult. The influence of support constraints may be important, because these will tend to hinder densification as discussed before. When evaporation takes place very fast due to the thin layer, this will result in a reduced time in which further condensation takes place, so promoting the formation of less porous materials with small micropores. So the ratio's of condensation rate, penetration rate and drying rate are important.

\section{Conclusions}

High quality $\gamma$-alumina membranes are used for the modification with microporous top-layers, resulting in enhanced gas transport properties. 
Non-supported $\gamma$-alumina top-layers have a porosity of $57 \%$ after calcination at $600^{\circ} \mathrm{C}$, with a pore radius (cylindrical geometry) of around $2.2 \mathrm{~nm}$. Supported membranes showed a slightly higher pore radius of 2.5 $\mathrm{nm}$. This difference is attributed to support constraints which hinder densification.

The top-layer of supported $\gamma$-alumina membranes is $7-10 \mu \mathrm{m}$ after three dipping procedures with boehmite dip solutions. A very fine surface roughness of $40 \mathrm{~nm}$ was obtained, and is necessary to obtain high quality microporous top-layers in a subsequent processing step.

Microporous silica top-layers have thicknesses in the order of $60-100 \mathrm{~nm}$. The surface roughness was not further decreased.

Microporous top-layers with interesting, molecular sieve-like gas transport properties have been obtained by modification with a broad range of sol structures; from oligomeric structures which show no scattering with SAXS, to polymeric sols with fractal dimensions to 2.04 .

Activation energies for hydrogen permeation are in the order of $5-17 \mathrm{~kJ} \mathrm{~mol}^{-1}$. typical permeation rates for hydrogen at $200^{\circ} \mathrm{C}$ are in the order of $10 \times 10^{-7}$ mol. $\mathrm{m}^{-2} \cdot \mathrm{s}^{-1} \cdot \mathrm{Pa}^{-1}$. Gas separation factors for $\mathrm{H}_{2} / \mathrm{CH}_{4}$ up to 200 have been found.

Repair of defects in microporous membranes was performed successfully by a single extra dipping step.

\section{Acknowledgements}

Special thanks to A.A. ten Hoeve and P.J.A.M. Blankenvoorde for their help related with synthesis and characterization of microporous membranes. A.J.H. van den Berg and M.A. Smithers of the Center for
Materials Research (CMO) of the University of Twente are thanked for performing respectively the SAM and FE-SEM analysis. G.W. Koebrugge is acknowledged for his help with the AFM experiments.

\section{Appendix: Support correction}

Appendix: support correction Corrections for the influence of the support system on the permeation of the microporous top-layer have to be performed to calculate the real pressure drop over the top-layer. In this work, the support system is the $\gamma$-alumina membrane, which is a composite membrane consisting of a $\gamma$ alumina top-layer on an $\alpha$-alumina support. We will further refer to the $\gamma$-alumina membrane as "support", and to the microporous silica layer as "top-layer". The corrections were performed by the series model [54,55], which requires knowledge of the permeation characteristics of the support. It is assumed that the resistance for permeation for the system is a series process of the support resistance and the top-layer resistance, where the permeation is a reciprocal resistance:

$\frac{1}{F_{0, \text { membrane }}}=\frac{1}{F_{0, \text { top-layer }}}+\frac{1}{F_{0 \text {,support }}}$

Support characteristics were determined with $\mathrm{H}_{2}$ permeation at room temperature. The total support permeation can then be expressed as:

$F_{0, \text { support }}=\alpha_{\mathrm{s}}+\beta_{\mathrm{s}} \cdot P_{\mathrm{av}}$

where $\alpha_{\mathrm{s}}$ expresses the Knudsen component, $\beta_{\mathrm{s}} . P_{\mathrm{av}}$ expresses the Poiseuille (laminar) flow component, and $P_{\text {av }}$ is the average pressure $\left(P_{\text {high }}-P_{\text {low }}\right)$. For the supports used in this work, mean values for $\alpha_{\mathrm{s}}$ and $\beta_{\mathrm{s}}$ for hydrogen at $25^{\circ} \mathrm{C}$ are, respectively, 62

Table 6

Example support correction $\mathrm{H}_{2}$ permeation data for membrane Al3-Si2-A

\begin{tabular}{lllllllll}
\hline Input & & \multicolumn{4}{c}{ Results } \\
\hline Temperature $\left({ }^{\circ} \mathrm{C}\right)$ & $P_{\text {high }}(\mathrm{bar})$ & $\Phi\left(\mathrm{mol}^{\left.-\mathrm{s}^{-1}\right)} \times 10^{-6}\right.$ & $\alpha_{\mathrm{s}}^{\mathrm{a}}$ & $\beta_{\mathrm{s}}^{\mathrm{b}}$ & $F_{0, \text { membrane }}^{\mathrm{a}}$ & $P_{\mathrm{i}}$ (bar) & $F_{0, \text { support }}^{\mathrm{a}}$ & $F_{0, \text { top }}^{\mathrm{a}}$ \\
\hline 50 & 2.065 & 7.11 & 44.0 & 3.2 & 1.80 & 0.0944 & 44.1 & 1.88 \\
250 & 0.71 & 7.11 & 35.0 & 1.4 & 6.77 & 0.118 & 34.6 & 8.42 \\
250 & 1.995 & 27.9 & 35.0 & 1.4 & 7.30 & 0.429 & 34.8 & 9.23 \\
\hline
\end{tabular}

${ }^{\mathrm{a}} 10^{-7} \mathrm{~mol} \cdot \mathrm{m}^{-2} \cdot \mathrm{s}^{-1} \cdot \mathrm{Pa}^{-1}$.

${ }^{2} 10^{-12} \mathrm{~mol} \cdot \mathrm{m}^{-2} \cdot \mathrm{s}^{-1} \cdot \mathrm{Pa}^{-2}$. 
ml.min ${ }^{-1} . \mathrm{cm}^{-2} . \mathrm{bar}^{-1}\left(\equiv 46.1 \times 10^{-7} \mathrm{~mol} . \mathrm{m}^{-2} . \mathrm{s}^{-1}\right.$. $\left.\mathrm{Pa}^{-1}\right)$ and $5 \mathrm{ml} \cdot \mathrm{min}^{-1} \cdot \mathrm{cm}^{-2} \cdot \mathrm{bar}^{-2}\left(\equiv 3.7 \times 10^{-12}\right.$ mol.m $\left.{ }^{-2} \cdot \mathrm{s}^{-1} \cdot \mathrm{Pa}^{-2}\right)$. The values for $\alpha_{\mathrm{s}}$ and $\beta_{\mathrm{s}}$ for other gases and/or different temperatures are calculated from the measured hydrogen data from the temperature dependency of the Knudsen diffusion component $\left(\alpha_{\mathrm{s}}\right)$ and the laminar flow component $\left(\beta_{\mathrm{s}}\right)$ [54]. From experiments with $\mathrm{He}$ and $\mathrm{H}_{2}$ between $25^{\circ} \mathrm{C}$ and $200^{\circ} \mathrm{C}$ it was found that the accuracy in calculating these flow components at different temperatures according to this estimate is around $5-10 \%$ [56]. The pressure at the interface $\left(P_{\mathrm{i}}\right)$ of the top-layer (microporous silica) and the support ( $\gamma$-alumina membrane) can than be calculated by $[54,55]$ :

$$
=\frac{-\alpha_{\mathrm{s}}+\left[\alpha_{\mathrm{s}}^{2}+\beta_{\mathrm{s}}\left(\beta_{\mathrm{s}} \cdot P_{1}^{2}+2 \cdot \alpha_{\mathrm{s}} \cdot P_{1}+2 \cdot \frac{\Phi}{S}\right)\right]^{1 / 2}}{\beta_{\mathrm{s}}}
$$

where $P_{1}$ is the pressure at the permeate side of the membrane, $S$ is the permeation area and $\Phi$ is the flow rate. The support permeation for the actual experiment is then given by:

$$
F_{0, \text { support }}=\frac{\Phi}{S .\left(P_{\mathrm{i}}-P_{1}\right)}
$$

Since now both the total permeation ( $\left.F_{0, \text { membrane }}\right)$ and the support permeation $\left(F_{0, \text { support }}\right)$ are known, Eq. (6) can be used to calculate the top-layer permeation $F_{0 \text {,top-layer }}$.

For example, some support correction data of membrane Al3-Si2-A (Fig. 13) is given in Table 6. The permeation area $(S)$ is $1.911 \mathrm{~cm}^{-2}$ and the pressure at the down-stream side $\left(P_{1}\right)$ is 0.01 bar. The values of $\alpha_{\mathrm{s}}$ and $\beta_{\mathrm{s}}$ at $50^{\circ} \mathrm{C}$ and $250^{\circ} \mathrm{C}$ are calculated as described before from the mean values; the viscosity $(\eta)$ of $\mathrm{H}_{2}$ at 25,50 and $250^{\circ} \mathrm{C}$ is, respectively, $0.889 \times 10^{-5}, \quad 0.944 \times 10^{-5}$ and $1.305 \times 10^{-5}$ N.s.m ${ }^{-2}$ [57].

$P_{\mathrm{i}}$, calculated from Eq. (8) using the corresponding flow rates $(\Phi)$, can be substituted in Eq. (9) to obtain the actual support permeation $F_{0 \text {,support. }}$

From the input data in Table 6 it can be clearly seen that increasing the temperature results in:

(i) Decreased support permeation rates, because both $\alpha_{\mathrm{s}}$ and $\beta_{\mathrm{s}}$ decrease.

(ii) Increased total permeation rates, due to activated transport. (iii) Decreased pressure drops over the membranes for the same gas flow. The relative pressure drop over the support (defined as $\left.P_{\mathrm{i}}-P_{1}\right) /\left(P_{\text {high }}-P_{1}\right)$ increases; at $50^{\circ} \mathrm{C}$ this is only $4 \%$, while this is $15 \%$ at $250^{\circ} \mathrm{C}$ (same gas flow).

Therefore, support correction is larger at higher temperatures.

\section{References}

[1] R.R. Bhave, Inorganic Membranes: Synthesis, Characteristics and Applications, Van Nostrand Reinhold, New York, 1991.

[2] K.S.W. Sing, D.H. Everett, R.A.W. Haul, L. Moscou, R.A. Pierotti, J. Rouquérol and T. Siemieniewska, Reporting physisorption data for gas/solid systems with special reference to the determination of surface area and porosity (IUPAC Recommendations 1984), Pure and Appl. Chem., 57 (1985) 603-619.

[3] A.J. Burggraaf, K. Keizer, R.S.A. de Lange, Z.A.E.P. Vroon and V.T. Zaspalis, Ceramic Membranes for Separations and Reactions, in J.B. Higgins, R. von Balmoos and M.M.J. Treacy (Eds.), Proceedings of the $9^{\text {th }}$ International Zeolite Conference, Montreal, Canada, July 5-10, 1992, ButterworthHeinemann, Stoneham, MA, 1993, pp. 47-71.

[4] R.J.R. Uhlhom, K. Keizer and A.J. Burggraaf, Gas transport and separation with ceramic membranes. Part II: Synthesis and separation properties of microporous membranes, J. Membrane Sci., 66 (1992) 271-288.

[5] S. Kitao, H. Kameda and M. Asaeda, Gas separation by thin porous silica membrane of ultra fine pores at high temperature, Membrane, 15 (1990) 222-227.

[6] R.S.A. de Lange, J.H.A. Hekkink, K. Keizer and A.J. Burggraaf, Preparation and characterization of microporous sol-gel derived membranes for gas separation applications, in M.J. Hampden-Smith, W.G. Klemperer and C.J. Brinker (Eds.), Better Ceramics through Chemistry V, Mater. Res. Symp. Proc., Vol. 271, Materials Research Society, Pittsburgh, 1992, pp. 505-510.

[7] C.J. Brinker, T.L. Ward, R. Sehgal, N.K. Raman, S.L. Hietala, D.M. Smith, D.-W. Hua and T.J. Headley, Ultramicroporous silica-based supported inorganic membranes, J. Membrane Sci., 77 (1993) 165-179.

[8] A. Julbe, C. Guizard, A. Larbot, L. Cot and A. Giroir-Fendler, The sol-gel approach to prepare candidate microporous inorganic membranes for membrane reactors, J. Membrane Sci., 77 (1993) 137-153.

[9] R.S.A. de Lange, K.-N.P. Kumar, J.H.A. Hekkink, G.M.H. van de Velde, K. Keizer, A.J. Burggraaf, W.H. Dokter, H.F. van Garderen and T.P.M. Beelen, Microporous $\mathrm{SiO}_{2}$ and $\mathrm{SiO}_{2} /$ $\mathrm{MO}_{\mathrm{x}}(\mathrm{M}=\mathrm{Ti}, \mathrm{Zr}, \mathrm{Al})$ for ceramic membrane applications; $\mathrm{A}$ microstructural study of the sol-stage and the consolidated state, 2 (1994) 489-495. 
[10] R.S.A. de Lange, Microporous Sol-gel Derived Ceramic Membranes for Gas Separation; Synthesis, Gas Transport and Separation Properties, Ph.D. Thesis, University of Twente, Enschede, The Netherlands, 1993.

[11] T. Okubo and H. Inoue, Single Gas permeation through porous glass modified with tetraethoxysilane, AIChE J., 35 (1989) 845-848.

[12] G.R. Gavalas, C.E. Megiris and S.W. Nam, Deposition of $\mathbf{H}_{2}$ permselective $\mathrm{SiO}_{2}$ films, Chem. Eng. Sci., 44 (1989) 18291835.

[13] M. Tsapatsis, S. Kim, S.W. Nam and G. Gavalas, Synthesis of hydrogen permselective $\mathrm{SiO}_{2}, \quad \mathrm{TiO}_{2}, \mathrm{Al}_{2} \mathrm{O}_{3}$ and $\mathrm{B}_{2} \mathrm{O}_{3}$ membranes from the chloride precursors, IEC Res., 30 (1991) 2152-2159.

[14] S. Kitao and M. Asaeda, Gas separation performance of thin porous silica membranes prepared by sol-gel and CVDmethods, Key Eng. Mater., $61 / 62$ (1991) 267-272.

[15] C.E. Megiris and J.H.E. Glezer, Synthesis of $\mathrm{H}_{2}$-permselective membranes by modified chemical vapor deposition. Microstructure and permselectivity of $\mathrm{SiO}_{2} / \mathrm{C} /$ vycor membranes, Ind. Eng. Chem. Res., 31 ( 1992) 1293-1299.

[16] Y.S. Lin, Chemical and Electrochemical Vapour Deposition of Zirconia-Yttria Solid Solutions in Porous Ceramic Media, Ph.D. Thesis, University of Twente, Enschede, The Netherlands, 1992.

[17] Y.S. Lin and A.J. Burggraaf, CVD of solid oxides in porous substrates for ceramic membrane modification, AIChE J., 38 (1992) 445-454.

[18] Y.S. Lin and A.J. Burggraaf, Experimental studies on pore size changes of porous ceramic membranes after modification, $\mathrm{J}$. Membrane Sci., 79 (1993) 65-82.

[19] G.Z. Cao, J. Meijerink, H.W. Brinkman, K.J. de Vries and A.J. Burggraaf, Growth of thin dense gas-tight $(\mathrm{Tb}, \mathrm{Y})-\mathrm{ZrO}_{2}$ films by electrochemical vapour deposition, J. Mater. Chem., 3 (1993) 773-774.

[20] J. Koresh and A. Soffer, Study of molecular sieve carbons. Part 1. Pore structure, gradual pore opening and mechanism of molecular sieving, J. Chem. Soc. Faraday Trans., 76 (1980) 2457-2471.

[21] M. Bhandarkar, A.B. Shelekhin, A.G. Dixon and Y.H. Ma, Adsorption, permeation and diffusion of gases in microporous membranes. I. Adsorption of gases on microporous glass membranes, J. Membrane Sci., 75 (1992) 221-231.

[22] A.B. Shelekhin, A.G. Dixon and Y.H. Ma, Adsorption, permeation, and diffusion of gases in microporous membranes. II. Permeation of gases in microporous glass membranes, $\mathbf{J}$. Membrane Sci., 75 (1992) 232-244.

[23] E.R. Geus, M.J. den Exter and H. van Bekkum, Synthesis and characterization of zeolite (MFI) membranes on porous ceramic supports, J. Chem. Soc. Faraday Trans. 1, 88 (1992) 3102-3109.

[24] W.J.W. Bakker, G. Zheng, F. Kapteijn, M. Makkee, J.A. Moulijn, E.R. Geus and H. van Bekkum, Single and Multicomponent Transport through Metal-Supported MFI Zeolite Membranes, in M.P.C. Weynen and A.A.H. Drinkenburg (Eds.), Precision Process Technology; Perspectives for
Pollution Prevention, Kluwer Academic Publishers, Dordrecht, The Netherlands, 1993, pp. 425-436.

[25] E.R. Geus, Preparation and Characterization of Composite Inorganic Zeolite Membranes with Molecular Sieve Properties, Ph.D. Thesis, Technical University of Delft, Delft, The Netherlands, 1993.

[26] M.D. Jia, K.V. Peinemann and R.D. Behling, Ceramic zeolite composite membranes. Preparation, characterization and gas permeation, J. Membrane Sci., 82 (1993) 15-26.

[27] A.F.M. Leenaars, K. Keizer and A.J. Burggraaf, The preparation and characterization of alumina membranes with ultra-fine pores. Part I Microstructural investigations on nonsupported membranes, J. Mater. Sci., 19 (1984) 1077-1088.

[28] A.F.M. Leenaars and A.J. Burggraaf, The preparation and characterization of alumina membranes with ultrafine pores. 2 The formation of supported membranes, J. Colloid Interface Sci., 105 ( 1985 ) 27-40.

[29] R.J.R. Uhlhorn, M.H.B.J. Huis in 't Veld, K. Keizer and A.J. Burggraaf, Synthesis of ceramic membranes. Part I. Synthesis of non-supported and supported $\gamma$-alumina membranes without defects, J. Mater. Sci., 27 (1992) 527-537.

[30] J. Kärger and D.M. Ruthven, Diffusion in Zeolites and other Microporous Materials, Wiley, New York, 1992.

[31] M.F.M. Post, Diffusion in Molecular Sieves, in H. van Bekkum, E.M. Flanigen and J.C. Jansen (Eds.), Introduction to Zeolite Science and Practice, Elsevier, Amsterdam, 1991, pp. 391443.

[32] R.S.A. de Lange, J.H.A. Hekkink, K. Keizer and A.J. Burggraaf, Permeation and separation studies on microporous sol-gel modified ceramic membranes, Microporous Solids, (1994) submitted.

[33] R.S.A. de Lange, K. Keizer and A.J. Burggraaf, Analysis and the theory of the gas transport mechanisms in microporous solgel derived membranes, J. Membrane Sci., (1995) accepted.

[34] C.J. Brinker, G.C. Frye, A.J. Hurd and C.S. Ashley, Review of sol-gel thin film formation, J. Non-Cryst. Solids, $147 / 148$ (1992) 424-436.

[35] B.B. Mandelbrot, The Fractal Geometry of Nature, Freeman, San Francisco, CA, 1983

[36] R.S.A. de Lange, J.H.A. Hekkink, K. Keizer and A.J. Burggraaf, Polymeric silica based sols for membrane modification applications; Sol-gel synthesis and characterization with SAXS, J. Non-Cryst. Solids, (1994) submitted.

[37] R.S.A. de Lange, J.H.A. Hekkink, K. Keizer and A.J. Burggraaf, Microstructural characterization of non-supported microporous ceramic membrane toplayers obtained by the solgel process, J. Non-Cryst. Solids, (1994) submitted.

[38] G.C. Frye, A.J. Ricco, S.J. Martin and C.J. Brinker, Characterization of the surface area and porosity of sol-gel films using SAW devices, in C.J. Brinker, D.E. Clark and D.R. Ulrich (Eds.), Better Ceramics Through Chemistry III, Mater. Res. Soc. Symp. Proc., Vol. 121, Materials Research Society, Pittsburgh, PA, 1988, pp. 349-354.

[39] E.P. Barrett, L.G. Joyner and P.P. Halenda, The determination of pore volume and area distributions in porous substances. I. Computations from nitrogen isotherms, J. Am. Chem. Soc., 73 (1951) 373-380. 
[40] S.J. Gregg and K.S.W. Sing, Adsorption, Surface Area and Porosity, Academic Press, London, 1982, Chapter 4.

[41] G.Z. Cao, J. Meijerink, H.W. Brinkman and A.J. Burggraaf, Permporometry study on the size distribution of active pores in porous ceramic membranes, J. Membrane Sci., 83 (1993) 221-235.

[42] L.E. Davis, N.C. McDonald, P.W. Palmberg, G.E. Riach and R.E. Weber, Handbook of Auger Spectroscopy, $2^{\text {nd }}$ edition, Physical Electronics, Edina M.N., 1987.

[43] D. Briggs and M.P. Seah, Practical Surface Analysis by Auger and X-ray Spectroscopy, Wiley, Chichester, 1983.

[44] F.P. Cuperus, D. Bargeman and C.A. Smolders, Permporometry. The determination of the size distribution of active pores in UF membranes, J. Membrane Sci., 71 (1992) $57-67$.

[45] V.T. Zaspalis, Catalytically Active Ceramic Membranes: Synthesis, Properties and Reactor Applications, Ph.D. Thesis, University of Twente, Enschede, The Netherlands, 1990.

[46] University of Twente, The Netherlands, unpublished results.

[47] K.-N.P. Kumar, K. Keizer, A.J. Burggraaf, T. Okubo and H. Nagamoto, Synthesis and textural properties of unsupported rutile $\left(\mathrm{TiO}_{2}\right.$ ) membranes, J. Mater. Chem., 3 (1993) 923-929.
[48] V.T. Zaspalis, On the Influence of Surface Roughness on Membrane Formation, Internal Report CT92/041/128, University of Twente, Enschede, The Netherlands, 1992.

[49] K.-N.P. Kumar, Nanostructured Ceramic Membranes. Layer and texture formation, Ph.D. Thesis, University of Twente, Enschede, The Netherlands, 1993, Chapter 2.

[50] P.C. Zalm, Quantitative sputtering, Surface Interface Anal., 11 (1988) 1-24

[51] D.W. Breck, Zeolite Molecular Sieves: Structure, Chemistry and Use, Wiley, New York, 1973, p. 636.

[52] R.W. Lee, Diffusion of hydrogen in natural and synthetic fused quartz, J. Chem. Phys., 38 ( 1963 ) 448-455.

[53] T. Ioannides and G.R. Gavalas, Catalytic isobutane dehydrogenation in a dense silica membrane reactor, J. Membrane Sci., 77 (1993) 207-220.

[54] R.J.R. Uhlhorn, Ceramic Membranes for Gas Separation: Synthesis and Transport Properties, Ph.D. Thesis, University of Twente, Enschede, The Netherlands, 1990.

[55] Y.S. Lin and A.J. Burggraaf, Preparation and characterization of high-temperature thermally stable alumina composite membrane, J. Am. Ceram. Soc., 74 (1991) 219-224.

[56] R.S.A. de Lange, unpublished results.

[57] C.F. Beaton and G.F. Hewitt, Physical Property Data for the Design Engineer, Hemisphere, New York, 1989. 